\title{
Numerical Simulation of the Natural Convection with Presence of the Nanofluids in Cubical Cavity
}

\author{
Mohamed Sannad (D), Abourida Btissam, and Belarche Lahoucine \\ National School of Applied Sciences, Ibn Zohr University, Agadir, BP 1136, Morocco \\ Correspondence should be addressed to Mohamed Sannad; mohamedsannad@gmail.com
}

Received 15 June 2020; Revised 14 October 2020; Accepted 22 October 2020; Published 21 November 2020

Academic Editor: Arkadiusz Zak

Copyright (c) 2020 Mohamed Sannad et al. This is an open access article distributed under the Creative Commons Attribution License, which permits unrestricted use, distribution, and reproduction in any medium, provided the original work is properly cited.

\begin{abstract}
This article consists of a numerical study of natural convection heat transfer in three-dimensional cavity filled with nanofluids. This configuration is heated by a partition maintained at a hot constant and uniform temperature $T_{H}$. The right and left vertical walls are kept at a cold temperature $T_{C}$ while the rest is adiabatic. The fluid flow and heat transfer in the cavity are studied for different sets of the governing parameters, namely, the nanofluid type, the Rayleigh number $\mathrm{Ra}=10^{3}, 10^{4}, 10^{5}$, and $10^{6}$, and the volume fraction $\Phi$ varying between $\Phi=0$ and 0.1 . The obtained results show a positive effect of the volume fraction and the Rayleigh number on the heat transfer improvement. The analysis of the results related to the heat transfer shows that the copperbased nanofluid guarantees the best thermal transfer. In addition, the increase of the heating section size and Ra leads to an increased amount of heat. Similarly, increasing the volume fraction improves the intensification of the flow and increases the heat exchange.
\end{abstract}

\section{Introduction}

The flow and heat transfers induced by natural convection have been considerably studied during these last decades because of their direct application in various fields of engineering such as air conditioning, energy efficiency, cooling of electronic components, etc. The previous works had mostly focused on the improvement of heat transfer induced by natural convection, which led to the development of a new research area based on the molecular structure of the fluid: modern nanotechnology, which can produce metallic or nonmetallic particles of nanometer dimensions. These nanomaterials, with average sizes below $100 \mathrm{~nm}$, have unique mechanical, optical, electrical, magnetic, and thermal properties and nanofluids are mixtures of these particles and traditional fluids such as water, oil, and ethylene glycol. Hence, a minimal amount of guest nanoparticles, when dispersed uniformly and suspended stably in host fluids, can provide improvements in the thermal properties of the host fluids.
The primary early interest in nanofluids from a technological viewpoint was the possibility of using these fluids for cooling purposes. Although the higher conductivity is an encouraging phenomenon of the cooling capabilities of such fluids, it is also important not only to reveal the convective behavior of nanofluids but also to understand the dynamics of fluids and the theories of heat transfer of nanofluids. Till now, convective studies of nanofluids have been very limited compared to experimental and theoretical studies on conduction.

Numerical work on the natural convection of nanofluids was carried out by Khanafer et al. [1]. They studied a differentially heated cavity with hot and cold vertical walls and adiabatic horizontal walls. They showed that the rate of heat transfer increases with an increase in the volume fraction of the nanoparticles for all the considered values of the Grashof number. In addition, they have shown that the heat transfer rate is favored when the volume fraction of the nanoparticles increases. Among the works dealing with heat transfer in the presence of nanoparticles, Murshed et al. [2] showed that the thermal conductivity increases with the increase of the 
volume concentration, and they also found that, for a volume concentration of $5 \%$, the improvement of the effective thermal conductivity is about $33 \%$ for the nanotubes and of $30 \%$ for spherical nanoparticles. They found that the size and shape of the particles have a significant influence on the thermal conductivity of nanofluids.

Similar work was carried out by Jou and Tzeng [3] inside a differentially heated cavity. They also used the stream function vorticity formulation in a way identical to that used in a previous study by Khanafer et al. [1]. In addition to the Grashof number effects, they then described the effect of the cavity aspect ratio (width/height) on thermal behavior. However, they concluded that, at $20 \%$ volume fractions, Newtonian behavior of the fluid is doubtful and it is extremely difficult to make stable nanofluids to use. Also, at such volume fractions, Newtonian behavior of the fluid is doubtful. A recent numerical study by Ho et al. [4] in a vertical square enclosure filled with a nanofluid (water$\mathrm{Al}_{2} \mathrm{O}_{3}$ ) shows clearly the effects of different parameters on flow simulation. They examined the effects of uncertainties due to the adoption of different models for thermal conductivity and dynamical viscosity. These authors found that the heat transfer through the enclosure could be enhanced or attenuated depending on the models used for the dynamical viscosity of the nanofluid. Hwang et al. [5] have made several measurements on the thermal conductivity of nanofluids and have shown that this parameter depends strongly on the volume fraction of the suspended particles and the thermal conductivity of the base fluid. Recently, Oztop and AbuNada [6] have numerically studied heat transfer and fluid flow as a function of buoyancy forces in a partially heated enclosure filled with nanofluids containing different types of nanoparticles. They showed that the improvement of the heat transfer was more pronounced for low values of the aspect ratio. They found that, for all the considered Rayleigh numbers, the average Nusselt number increases as the volume fraction of the nanoparticles increases.

Anilkumar and Jilani [7] presented a numerical investigation on the natural convection of a mixture of ethylene glycol and aluminum oxide in an enclosure heated by an isothermal partition located on its lower wall. The study indicates the influence of the nanoparticle volume fraction, the Rayleigh number, and the shape ratio of the enclosure on the dynamical and thermal behavior of the fluid. The results obtained show that the heat transfer improves with the increase of the volume fraction of the nanoparticles, and the presence of the nanoparticles in the base fluid modifies the structure of the flow. Natural convection in an inclined square enclosure heated by a source placed in the center of the left wall was studied by Ögüt [8]. The cavity was filled with a mixture of water and nanoparticles $(\mathrm{Cu}, \mathrm{Ag}, \mathrm{CuO}$, $\mathrm{Al}_{2} \mathrm{O}_{3}$, and $\mathrm{TiO}_{2}$ ), and the results show that the type of nanoparticle is a major factor in improving heat transfer.

Hussein et al. [9] investigated numerically the magnetohydrodynamic (MHD) natural convection flow of $\mathrm{Cu}$-water nanofluid in an open enclosure using lattice Boltzmann method (LBM) scheme. They found that the absolute values of stream function decline significantly by increasing Hartmann numbers while these values rise by increasing
Rayleigh numbers. In addition, they have shown that, depending on the value of the Hartmann and Rayleigh numbers, the solid volume fraction has a significant influence on the function of flux and heat transfer. The authors in [10] studied numerically the natural convection in three types of inclined wavy cavities filled with $\mathrm{Al}_{2} \mathrm{O}_{3}$-water and Ag-water nanofluids and subjected to a discrete isoflux heating from its left sidewall. They found that the geometry of the wavy cavity has a cursive role on the flow and thermal fields pattern. Also, the local Nusselt number along the heat source increases with the solid volume fractions and wave amplitudes and the heat functions increase for both nanofluids and base fluids with these parameters. The same authors have other articles in this context (Hussein et al. [11-13]).

The effects of the inclination angle of an external magnetic force on the natural convection inside a cubical cavity filled with a carbon nanotube- (CNT-) water nanofluid are investigated by Al-Rashed et al. [14]. They found that, for larger Rayleigh number, the heat transfer is increased significantly with the percentage of CNT particles. Moreover, they observed that a repelling effect of the magnetic force inhibits the heat transfer by $50 \%$ when $\mathrm{Ha}$ is increased from 50 to 100 . In another work [15], they investigated the effect of magnetic field on convective heat transfer of highly electrically conductive fluids taking into consideration the case of a low-conductive $\mathrm{LiNbO}_{3}$ oxide melt. Chand et al. [16] presented a numerical investigation of the thermal instability in a low Prandtl number nanofluid in a porous medium. They indicated that the Prandtl and Darcy numbers have a destabilizing effect while the Lewis number and modified diffusivity ratio have a stabilizing effect for the stationary convection.

Hussein et al. $[17,18]$ have studied two numerical cases in a three-dimensional cavity filled with nanofluids. The first study concerns natural convection and the second the mixed convection. For the first one, they found that the generation of total entropy becomes insignificant under the effect of the tilt angle for the low Rayleigh number. In addition, the flow circulation and the average Nusselt number increase with Rayleigh number. In the second study, they indicated that the average Nusselt number increases with the increase in the Richardson number and the solid volume fraction of the nanoparticles.

Kolsi et al. [19] performed a numerical investigation on the effect of a periodic magnetic field inside a cubical enclosure filled with nanofluids (Multi-Walled Carbon Nanotubes). They mentioned that the oscillation period, the magnitude of the magnetic field, and adding nanoparticles have an important effect on heat transfer, temperature field, and flow structure. Haq et al. [20-22] analyzed the heat transfer with a presence of the Magnetohydrodynamic (MHD) water-based Single-Wall Carbon Nanotubes (SWCNTs), the water-based copper oxide $(\mathrm{CuO})$ nanofluid, and uniform magnetic field. They, respectively, concluded that the increase of the Rayleigh number enhances the stream flow and isotherms behaviors. However, the heat transfer rate inside the cavity is decreasing with the increase in volume fraction, Hartmann number, and $L_{T}$ due to 
dominant convection. In addition, this transfer rate is increased due to increase in Rayleigh number and wavelength parameter. In addition, they observed that Darcy and Hartmann number do not have significant effects on the temperature distribution.

Muhammad et al. [23] investigated numerically the mixed convection flow of Ag-ethylene glycol nanofluid flow in a cavity having thin central heater. Their results, which are expressed by isotherms, streamlines, velocity field, and average Nusselt numbers, show that the heat transfer for Fourier's law is improved as compared to the results obtained for the case of Cattaneo-Christov heat flux. The augmentation of heat transfer in most of these studies was attributed to the virtue of the abnormal enhancement of the nanofluid thermal conductivity [24-26].

In a study by Guiet et al. [27], the laminar natural convection of a mixture of water and copper nanoparticles was numerically studied by the Boltzmann method in a square cavity heated from below and cooled laterally. The heating is provided by a block, which is either kept at a constant temperature or subjected to constant heat flow. This authors used the Brinkman [28] and the Patel et al. [29] models to calculate ,respectively, the effective viscosity and thermal conductivity of the nanofluid. Almeshaal et al. [30] had studied numerically the effect of water-based hybrid nanofluid of CNT-aluminum oxide on natural convection inside the T-shaped cavity. They found that the heat transfer performance manifests as a function of the size, volumetric percentage of nanoparticles, fraction of CNT composites, and Rayleigh number. Similarly, with the explosive advances in nanofluids in recent years, adding nano-sized metal particles in impinging cooling fluids has also received great interest from the community of process intensification for heat dissipation equipment [31-34].

The industrial applications of the heat transfer by natural convection are the electronic component cooling, the nuclear reactors, and the heat losses in solar collectors. Our study is part of this framework, particularly related to the intensification of heat change in the electronic component. The major studies cited considered two-dimensional cavity, but in our case, we are going to consider three-dimensional cavity. The fundamental parameters of the problem are the Rayleigh number, the volume fraction of the nanoparticles, and the dimensions and position of the heating block. The results of the study show that the heat transfer improves with the increase of the volume fraction of the nanoparticles independently of the boundary conditions applied on the heating block. Flow and heat transfer are significantly affected by the size of the heating source. Hence, the purpose of the present investigation is to study numerically the laminar natural convection in a cubical enclosure filled with nanofluid. The temperature distributions, the velocity patterns, and the heat transfer rates are analyzed and discussed in this paper.

\section{Problem Formulation}

The physical model considered is shown schematically in Figure 1. It consists of three-dimensional cavity of length $(H)$, filled with nanofluids and heated by the partition.

The mathematical model used in this paper is based on the Navier-Stokes and energy equations. These equations are discretized by the finite volume method, taking into account the Boussinesq approximation and neglecting the viscous dissipation. The physical parameters are given by the following equations:

(i) The density [35]:

$$
\rho_{n f}=(1-\phi) \rho_{f}+\phi \rho_{n p} .
$$

(ii) The heat capacitance of the nanofluid [35]:

$$
\left(\rho C_{p}\right)_{n f}=(1-\phi)\left(\rho C_{p}\right)_{f}+\phi\left(\rho C_{p}\right)_{n p} .
$$

(iii) Thermal expansion coefficient [35]:

$$
\beta_{n f}=(1-\phi) \beta_{f}+\phi \beta_{n p} .
$$

(iv) The dynamical viscosity of the nanofluid:

Brinkman [28] has extended the Einstein formula to cover a wide range of volumetric concentrations, which gives the following relation:

$$
\mu_{n f}=\frac{\mu_{f}}{(1-\phi)^{2.5}} .
$$

(v) Thermal diffusivity of nanofluids:

$$
\alpha_{n f}=\frac{k_{n f}}{\left(\rho C_{p}\right)_{n f}} .
$$

(vi) The thermal conductivity of nanofluids:

The formula of Maxwell [36] is given by

$$
\frac{k_{n f}}{k_{f}}=\frac{k_{n p}+2 k_{f}-\left[2\left(k_{f}-k_{n p}\right) \phi\right]}{k_{n p}+2 k_{f}+\left[\phi\left(k_{f}-k_{n p}\right)\right]},
$$

$k_{n f}, k_{f}$ and $k_{n p}$ are, respectively, the thermal conductivities of the nanofluid, the basic fluid, and the solid 
nanoparticles. The thermophysical properties of the basic fluid, water, and the considered nanoparticles are given in Table 1.
The governing equations can be written as follows:

$$
\begin{aligned}
\frac{\partial u}{\partial x}+\frac{\partial v}{\partial y}+\frac{\partial w}{\partial z} & =0 \\
\rho_{n f}\left(\frac{\partial u}{\partial t}+u \frac{\partial u}{\partial x}+v \frac{\partial u}{\partial y}+w \frac{\partial u}{\partial z}\right) & =-\frac{\partial P}{\partial x}+\mu_{n f}\left(\frac{\partial^{2} u}{\partial x^{2}}+\frac{\partial^{2} u}{\partial y^{2}}+\frac{\partial^{2} u}{\partial z^{2}}\right) \\
\rho_{n f}\left(\frac{\partial v}{\partial t}+u \frac{\partial v}{\partial x}+v \frac{\partial v}{\partial y}+w \frac{\partial v}{\partial z}\right) & =-\frac{\partial P}{\partial y}+\mu_{n f}\left(\frac{\partial^{2} v}{\partial x^{2}}+\frac{\partial^{2} v}{\partial y^{2}}+\frac{\partial^{2} v}{\partial z^{2}}\right)-\rho_{n f} g \\
\rho_{n f}\left(\frac{\partial w}{\partial t}+u \frac{\partial w}{\partial x}+v \frac{\partial w}{\partial y}+w \frac{\partial w}{\partial z}\right) & =-\frac{\partial P}{\partial z}+\mu_{n f}\left(\frac{\partial^{2} w}{\partial x^{2}}+\frac{\partial^{2} w}{\partial y^{2}}+\frac{\partial^{2} w}{\partial z^{2}}\right) \\
\frac{\partial T}{\partial t}+u \frac{\partial T}{\partial x}+v \frac{\partial T}{\partial y}+w \frac{\partial T}{\partial z} & =\alpha_{n f}\left(\frac{\partial^{2} T}{\partial x^{2}}+\frac{\partial^{2} T}{\partial y^{2}}+\frac{\partial^{2} T}{\partial z^{2}}\right)
\end{aligned}
$$

In order to limit the number of variables involved in the problem under study, the system of equations is dimensionalized by considering dimensionless parameters based on reference quantities as presented in Table 2.
Therefore, the governing equations of continuity, momentum, and energy conservation for stable laminar flow in Cartesian coordinates can be written in the following dimensionless form:

$$
\begin{aligned}
\frac{\partial U}{\partial X}+\frac{\partial V}{\partial Y}+\frac{\partial W}{\partial Z} & =0 \\
U \frac{\partial U}{\partial X}+V \frac{\partial U}{\partial Y}+W \frac{\partial U}{\partial Z} & =-\frac{\partial P}{\partial X}+\frac{\mu_{n f}}{\alpha_{f} \rho_{n f}}\left(\frac{\partial^{2} U}{\partial X^{2}}+\frac{\partial^{2} U}{\partial Y^{2}}+\frac{\partial^{2} U}{\partial Z^{2}}\right) \\
U \frac{\partial V}{\partial X}+V \frac{\partial V}{\partial Y}+W \frac{\partial V}{\partial Z} & =-\frac{\partial P}{\partial Y}+\operatorname{Ra} * \operatorname{Pr} * \theta * \frac{\rho_{f} \beta_{n f}}{\rho_{n f} \beta_{f}}+\frac{\mu_{n f}}{\alpha_{f} \rho_{n f}}\left(\frac{\partial^{2} V}{\partial X^{2}}+\frac{\partial^{2} V}{\partial Y^{2}}+\frac{\partial^{2} V}{\partial Z^{2}}\right) \\
U \frac{\partial W}{\partial X}+V \frac{\partial W}{\partial Y}+W \frac{\partial W}{\partial Z} & =-\frac{\partial P}{\partial Z}+\frac{\mu_{n f}}{\alpha_{f} \rho_{n f}}\left(\frac{\partial^{2} W}{\partial X^{2}}+\frac{\partial^{2} W}{\partial Y^{2}}+\frac{\partial^{2} W}{\partial Z^{2}}\right) \\
U \frac{\partial \theta}{\partial X}+V \frac{\partial \theta}{\partial Y}+W \frac{\partial \theta}{\partial Z} & =\frac{\alpha_{n f}}{\alpha_{f}}\left(\frac{\partial^{2} \theta}{\partial X^{2}}+\frac{\partial^{2} \theta}{\partial Y^{2}}+\frac{\partial^{2} \theta}{\partial Z^{2}}\right) .
\end{aligned}
$$

The adopted thermal boundary conditions are as follows: $\theta=-0.5$, on the cold wall, and $\theta=0.5$, on the heated partition.

$(\partial \theta / \partial n)=0$ on the adiabatic walls.

The adopted hydrodynamic boundary conditions are as follows:

$$
U=V=W=0 \text { for all walls. }
$$

The average Nusselt number, $\mathrm{Nu}_{\mathrm{a}}$, is defined as the integral of the temperature flux through the vertical right cold wall and formulated as

$$
\mathrm{Nu}_{\mathrm{a}}=\frac{k_{n f}}{k_{f}} \int_{S} \vec{\nabla} \theta \cdot \vec{e}_{x} \mathrm{~d} y \mathrm{~d} z .
$$

\section{Materials and Methods}

3.1. Mesh. It is the subdivision of the studied field into volume elements in the $X$ direction, $Y$ direction, and $Z$ direction whose intersection represents a node, where the variables $P$ and $T$ are found. The $U, V$, and $W$ components of the velocity vector are located in the middle of the faces connecting two adjacent nodes. The discretization of the domain is obtained by a mesh consisting of a network of 


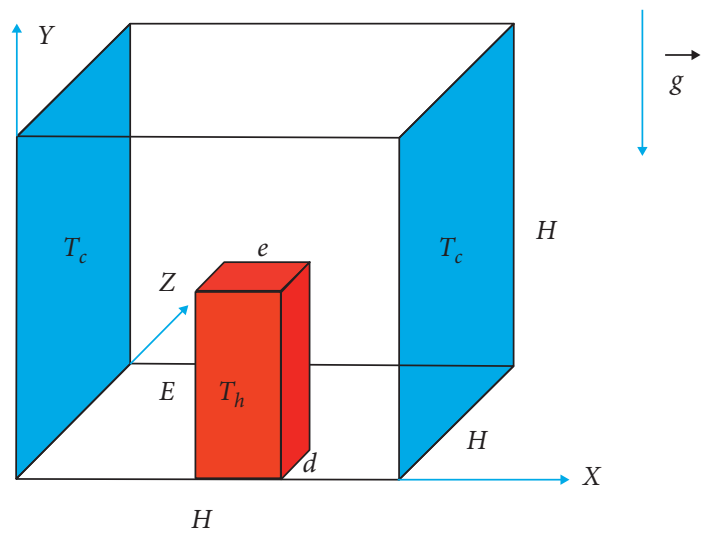

FIgURE 1: Studied configurations and coordinates.

TABLE 1: Thermophysical properties of pure water and nanoparticles.

\begin{tabular}{lcccc}
\hline & $\rho\left(\mathrm{kg} \cdot \mathrm{m}^{-3}\right)$ & $\beta\left(\mathrm{K}^{-1}\right)$ & $k\left(\mathrm{~W} \cdot \mathrm{m}^{-1} \cdot \mathrm{K}^{-1}\right)$ & $C p\left(\mathrm{~J} \cdot \mathrm{kg}^{-1} \cdot \mathrm{K}^{-1}\right)$ \\
\hline Pure water & 997.1 & $21 \times 10^{-5}$ & 0.613 & 4179 \\
$\mathrm{Al}_{2} \mathrm{O}_{3}$ & 3970 & $0.85 \times 10^{-5}$ & 40 & 765 \\
$\mathrm{Cu}$ & 8933 & $1.67 \times 10^{-5}$ & 400 & 385 \\
$\mathrm{TiO}_{2}$ & 4250 & $0.90 \times 10^{-5}$ & 8.9538 & 686.2 \\
\hline
\end{tabular}

TABLE 2: Dimensionless parameters.

\begin{tabular}{lcc}
\hline & Dimensionless variables & References variables \\
\hline Spatial coordinates & $(X, Y, Z)=\left((x, y, z) / L_{\text {ref }}\right)$ & $L_{\text {ref }}=H$ \\
Velocity & $(U, V, W)=\left((u, v, w) / V_{\text {ref }}\right)$ & $V_{\text {ref }}=\left(\alpha_{f} / H\right)$ \\
Pressure & $P=\left(\left(p+\rho_{0} g y\right) / P_{\text {ref }}\right)$ & $P_{\text {ref }}=\left(\rho_{n f} \alpha_{f}^{2} / H^{2}\right)$ \\
Temperature & $\theta=\left(\left(T-T_{\text {ref }}\right) / \Delta T\right)$ & $\Delta T=T_{C}-T_{F}$ with $T_{\text {ref }}=\left(\left(T_{C}+T_{F}\right) / 2\right)$ \\
\hline
\end{tabular}

points (nodes). Thus, a volume element (control volume) is defined around each node. In order to obtain a fine mesh at the level of the active walls ( $X=0$ and $X=1)$, the computational domain has been discretized by adopting a mesh that is non-uniform in the $X$ direction and uniform in the $Y$ and $Z$ directions. To test the influence of the number of nodes on the obtained results, we solved the transport equations for mesh sizes of $41 \times 41 \times 41,51 \times 51 \times 51,61 \times 61 \times 61,71 \times 71 \times 71$, and $81 \times 81 \times 81$ and $\mathrm{Ra}=10^{5}$ (Table 3 ). Following this mesh sensitivity test, we chose the $61 \times 61 \times 61$ mesh.

3.2. Validation. A numerical code was developed based on the finite volume method to discretize the governing equations. The conservation equations of momentum coupled with the continuity equation are solved using the algorithm SIMPLE. The resolution of the obtained discrete algebraic system is based on the Alternating Direction Implicit (ADI) scheme. The code was then validated by comparing our results with those obtained in two different cases for a differentially heated three-dimensional cavity: the first case concerns a three-dimensional cavity filled with nanofluids (Ravnik et al. [37]) and the second is related to a three-dimensional cavity filled with air (Lo et al. [38] (Table 4)). It is clear that the results of our code are in good agreement with those proposed by Ravnik et al. [37] (Figure 2 and Table 5). Indeed, the maximum deviation is of the order of $3.59 \%$.

3.3. Convergence Criterion. The partial differential equations and the method applied to solve the resulting algebraic system require iterative calculation. In an iterative process, we must start with an evaluation of the solution, which does not automatically check the equation to be solved. When subsequent iterations produce no significant change in the values of the dependent variables $\phi$, convergence is said to have been achieved. In practice, this convergence is expressed by a test used to stop the iterative process, also called the convergence criterion, which depends on the nature of the problem and the objectives of the calculation.

By adopting the procedure used by Penot [39], this test can be carried out, for a given variable, as follows:

$$
\sum_{i, j, k=1}^{i \max , j \max , k \max } \frac{\left|\phi_{i, j, k}^{n+1}-\phi_{i, j, k}^{n}\right|}{\left|\phi_{i, j, k}^{n}\right|} \leq 10^{-5}
$$

where $\phi$ represents the field variables $(U, V, W, T, P)$. The subscripts $i, j$, and $k$ are the points of the mesh. The 
TABle 3: Mesh sensitivity of the average Nusselt number to the grid sizes.

\begin{tabular}{lccccc}
\hline & $41 \times 41 \times 41$ & $51 \times 51 \times 51$ & $61 \times 61 \times 61$ & $71 \times 71 \times 71$ & $81 \times 81 \times 81$ \\
\hline $\mathrm{Nu}_{\text {moy }}$ & 4.948685 & 4.921563 & 4.898485 & 4.895235 & 4.892066 \\
\hline
\end{tabular}

TABLE 4: Comparison of the average Nusselt number between our results and those of Lo et al. [38].

\begin{tabular}{lccc}
\hline & Lo et al. [38] & Our study & Relative gap (\%) \\
\hline $\mathrm{Ra}=10^{3}$ & 1.0710 & 1.0770 & 0.56 \\
$\mathrm{Ra}=10^{4}$ & 2.0537 & 2.0932 & 1.9 \\
$\mathrm{Ra}=10^{5}$ & 4.3329 & 4.4329 & 2.3 \\
$\mathrm{Ra}=10^{6}$ & 8.6678 & 8.8997 & 2.6 \\
\hline
\end{tabular}

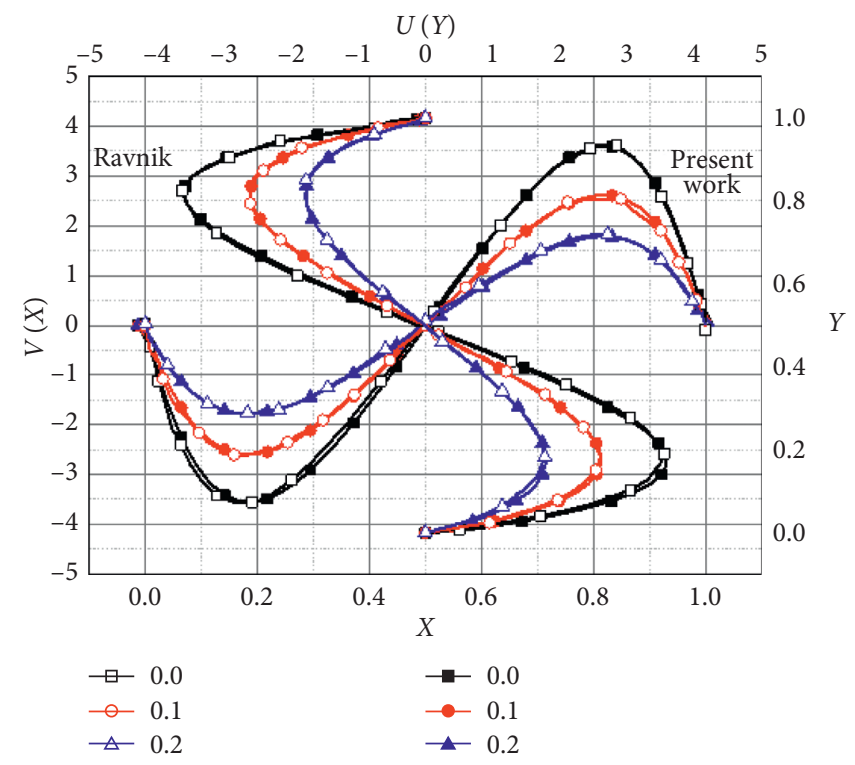

FIGURE 2: Comparison of the velocity between our results and those of Ravnik et al. [37] for $\phi=0,0.1$, and 0.2.

TABle 5: Comparison of the mean Nusselt number between our results and those of Ravnik et al. [37] for different types of nanofluids and values of volume fraction $(\phi=0.0,0.1$, and 0.2$)$.

\begin{tabular}{|c|c|c|c|c|c|c|c|c|}
\hline & \multirow{2}{*}{$\mathrm{Ra}$} & \multirow{2}{*}{$\begin{array}{l}\text { Water } \\
\phi=0.0\end{array}$} & \multicolumn{2}{|c|}{ Water-Cu } & \multicolumn{2}{|c|}{ Water- $\mathrm{Al}_{2} \mathrm{O}_{3}$} & \multicolumn{2}{|c|}{ Water- $\mathrm{TiO}_{2}$} \\
\hline & & & $\phi=0.1$ & $\phi=0.2$ & $\phi=0.1$ & $\phi=0.2$ & $\phi=0.1$ & $\phi=0.2$ \\
\hline Ravnik et al. & $10^{3}$ & 1.071 & 1.363 & 1.758 & 1.345 & 1.718 & 1.297 & 1.598 \\
\hline This work & $10^{3}$ & 1.080 & 1.371 & 1.767 & 1.353 & 1.727 & 1.304 & 1.607 \\
\hline Relative gap & $10^{3}$ & $0.84 \%$ & $0.58 \%$ & $0.51 \%$ & $0.59 \%$ & $0.52 \%$ & $0.53 \%$ & $0.56 \%$ \\
\hline Ravnik et al. & $10^{4}$ & 2.078 & 2.237 & 2.381 & 2.168 & 2.244 & 2.115 & 2.132 \\
\hline This work & $10^{4}$ & 2.121 & 2.277 & 2.415 & 2.206 & 2.275 & 2.153 & 2.162 \\
\hline Relative gap & $10^{4}$ & $2.06 \%$ & $1.78 \%$ & $1.42 \%$ & $1.75 \%$ & $1.38 \%$ & $1.79 \%$ & $1.4 \%$ \\
\hline Ravnik et al. & $10^{5}$ & 4.510 & 4.946 & 5.278 & 4.806 & 4.968 & 4.684 & 4.732 \\
\hline This work & $10^{5}$ & 4.672 & 5.095 & 5.409 & 4.948 & 5.086 & 4.823 & 4.845 \\
\hline Relative gap & $10^{5}$ & $3.59 \%$ & $3.01 \%$ & $2.48 \%$ & $2.95 \%$ & $2.37 \%$ & $2.96 \%$ & $2.38 \%$ \\
\hline
\end{tabular}

exponents $n$ and $n+1$ represent the previous iteration and the current iteration, respectively. The parameter $\varepsilon_{1}=10^{-5}$ has been chosen small enough to avoid truncation errors while remaining above rounding errors [40, 41].

\section{Results and Discussion}

The results presented in this article are obtained for Rayleigh numbers $\mathrm{Ra}$ ranging between $10^{3}$ and $10^{6}$ and the 
volume fraction equal to 0 and 0.1 . The Prandtl number is fixed at $\operatorname{Pr}=6.2$ (water). Isotherms and streamlines are presented in order to illustrate the nanofluid motion and the heat transfer within the cavity. Interesting results have been found, in terms of fluid flow and heat transfer through the cavity, depending on the adopted values of the governing parameters and also the nature of the used nanofluid.

4.1. Flow and Temperature Fields. Figure 3 shows the distribution of the temperature in the three-dimensional cavity for different lengths $d, \mathrm{Ra}=10^{5}$, and $\phi=0.04$. The figure illustrates that fluid movement occurs from the partition to the cold walls so that the heat transfer rate is maintained permanently in the cavity and this phenomenon is done by convection due to the high thermal gradients in the active walls, for that value of Ra. The increase in the heating surface, resulting from the increase in the length $d$, naturally leads to an increase in the energy supplied to the heat transfer fluid. In order to have a better view of the temperature profile within the cavity (in $3 \mathrm{D}$ ), different planes were considered. Thus, the plan chosen for the rest of our study will be that corresponding to $Z=1 / 2$ and which passes perpendicularly through the middle of component 1 . This plane suitably represents the flow and heat transfer within the cavity and being the most representative. The results presented are the results of simulations carried out by taking a Rayleigh number varying between $10^{3}$ and $10^{6}$ and a heating partition varying from 20 to $80 \%$ of the left vertical wall.

4.2. Isotherms and Streamlines. Figure 4 shows the current lines (left) and isotherms (right) for the nanofluid (water$\mathrm{Al}_{2} \mathrm{O}_{3}$ ) in the plane $Y=0.5$, for different dimensionless partition lengths, $\mathrm{Ra}=10^{5}$, and volume fraction $\phi=4 \%$. It can be seen that the increase in the length of the heating partition leads to an increase in flow resistance and consequently the intensity of the longitudinal flow decreases. For a length $d=0.75$, the distance between the partition and the vertical wall of the cavity (located at $Z=1$ ) becomes small and consequently causes a decrease in the intensity of the longitudinal flow of the fluid passing through the passage located between the planes located between $Z=0.75$ and $Z=1$. The fluid that is heated by the block moves towards the adiabatic upper wall, where it splits into two flows heading towards the cold vertical walls. This configuration leads to the formation of almost identical counter-rotating cells and a symmetrical flow structure compatible with the symmetry of the boundary conditions. Note also that the increased length of the partition contributes to the generalization of the flow in almost the entire cavity through larger, resistant convective cells. The corresponding isotherms become more constricted near the cold vertical walls.

Figure 5 illustrates the structure of the left streamlines and the right isotherms in plan $Z$ for nanofluid $\left(\mathrm{Al}_{2} \mathrm{O}_{3}\right)$ and pure water with the length $d=0.5$; the temperature distribution has different behavior near the active zones for different values of the Rayleigh number. In fact, increasing "Ra" improves the heat transfer from the warm walls of the cavity to the cold ones as shown in this figure. For the low value of Rayleigh number $\left(\mathrm{Ra}=10^{3}\right.$ and $\left.10^{4}\right)$, the viscous forces are greater than the buoyancy forces and diffusion is the main heat transfer mode. The figure shows that the flow consists of two cells occupying the entire cavity whose nuclei are located in the center. For low $\mathrm{Ra}$, the viscosity determines the intensity of the convection motion, due to the decreasing of the driving force for both fluids, that is, the water, which has the greatest intensity for these moderate Rayleigh numbers. The fluid that is heated by the heating walls moves to the adiabatic upper wall, where the flow goes to the right and left vertical cold walls, because the density of the heated fluid decreases and so moves upwards, and that is the flow intensity of the pure fluid which is the strongest. The temperature field is stratified along the diagonal of the cavity and the thermal gradients are weak in the vicinity of the active walls. On the other hand, for high $\mathrm{Ra}$, the nanofluid circulates faster than water due to increasing of the buoyancy force. The shape of the isotherms changes under the effect of the viscosity, which is due to the change in the heat transfer mode, which goes from conduction to convection when increasing the $\mathrm{Ra}$. The fluid motion drives the heat of the active areas through the cavity. When $\mathrm{Ra}=10^{6}$, the thermal boundary layers become thinner and the isotherms become laminated in the central region of the cavity. The increase of the stratification is a function of the position and the dimension of the heated source (Figure 4). For $\mathrm{Ra}=10^{3}$, the isotherms display a symmetrical structure with respect to the vertical plane passing through $X=1 / 2$. For a fixed value of the Rayleigh number, the degree of increase of the stratification with the increase of the dimensionless length of the heating source becomes important. The profiles show that, for the low values of $\mathrm{Ra}\left(\mathrm{Ra} \leq 10^{4}\right)$, the temperature increases away from the left cold wall $(\theta=-0.5)$ with the increase of Ra until reaching the value $\theta=0.175$ for $X=1 / 2$ above the heating partition. This temperature decreases gradually until reaching the value -0.5 on the opposite cold wall of the enclosure. For $\mathrm{Ra} \geq 10^{5}$, the temperature increases from the value -0.5 at the level of the cold wall located at $X=0$ until reaching its maximum value. This behavior is due to the buoyancy force that becomes important and subsequently the heat transfer mode goes from conduction to convection. This will lead to significant heat transfer within the cavity for the nanofluids and the base fluid (water) and much of this transfer is by convection. It is also noted that, for different values of the Rayleigh number, as the heat exchange surface increases, consequently the temperature increases significantly.

In this part, the influence of different types of nanoparticles $\left(\mathrm{Al}_{2} \mathrm{O}_{3}, \mathrm{Cu}\right.$, and $\left.\mathrm{TiO}_{2}\right)$ dispersed in the base fluid on the heat transfer is studied. Numerical simulations are performed for different Ra and volume fraction $\phi=0.04$. The comparisons conducted between the three types of nanoparticles concern primarily the dynamic and thermal fields, 


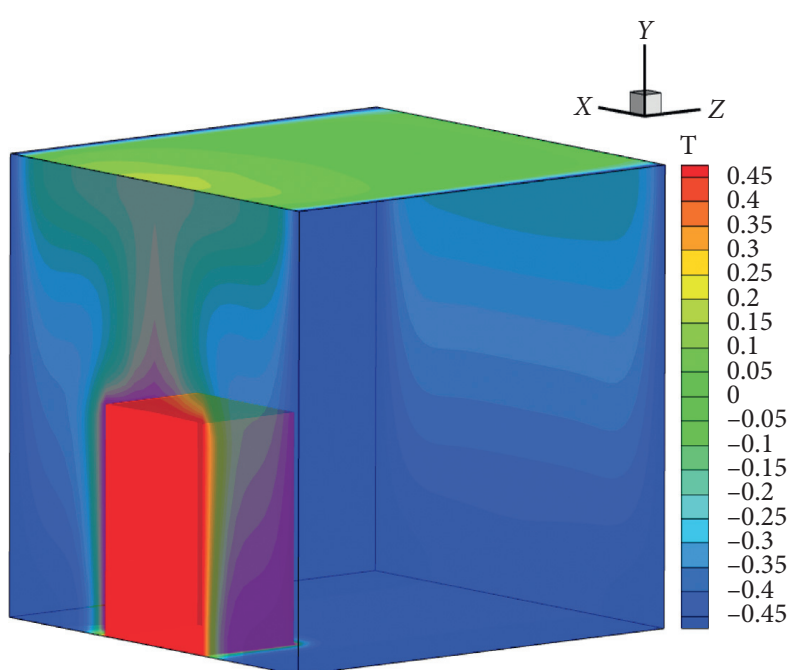

(a)

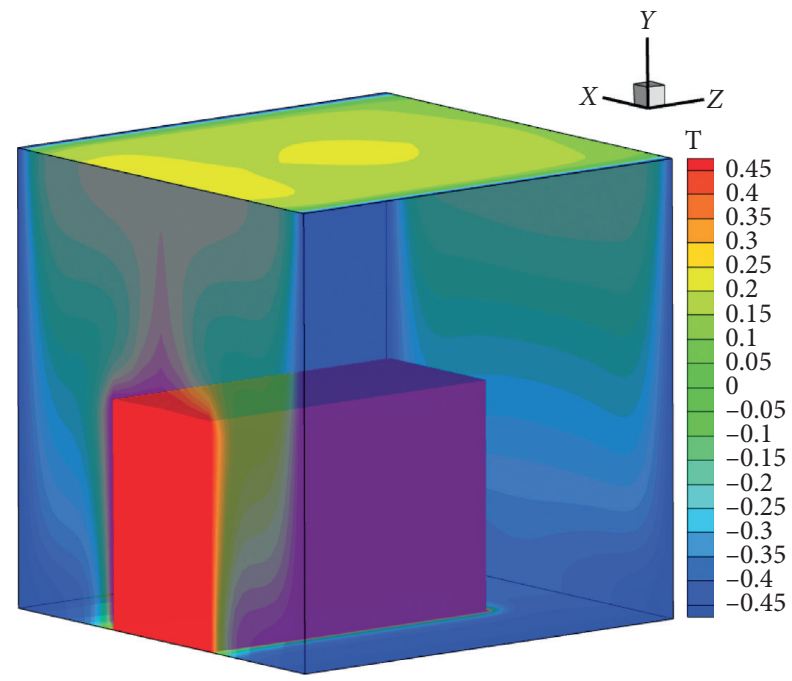

(c)

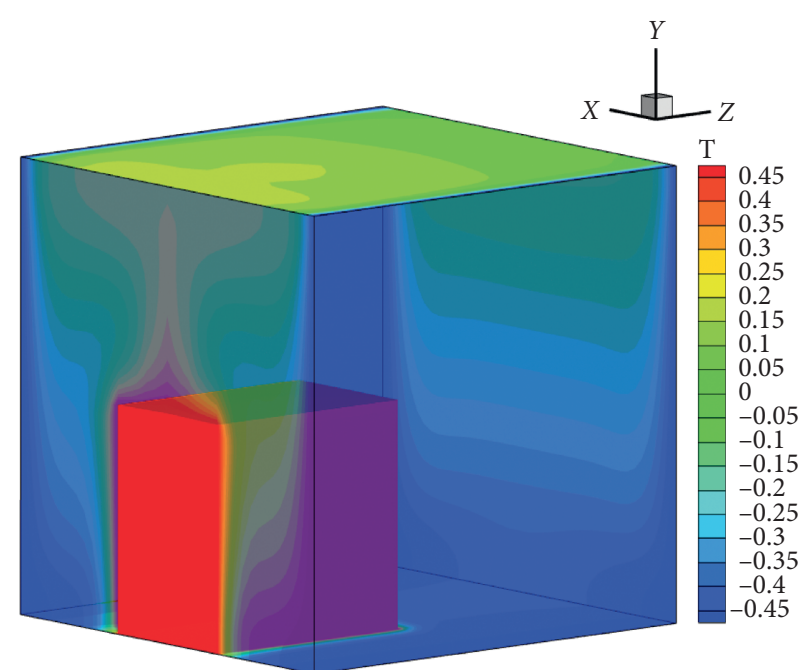

(b)

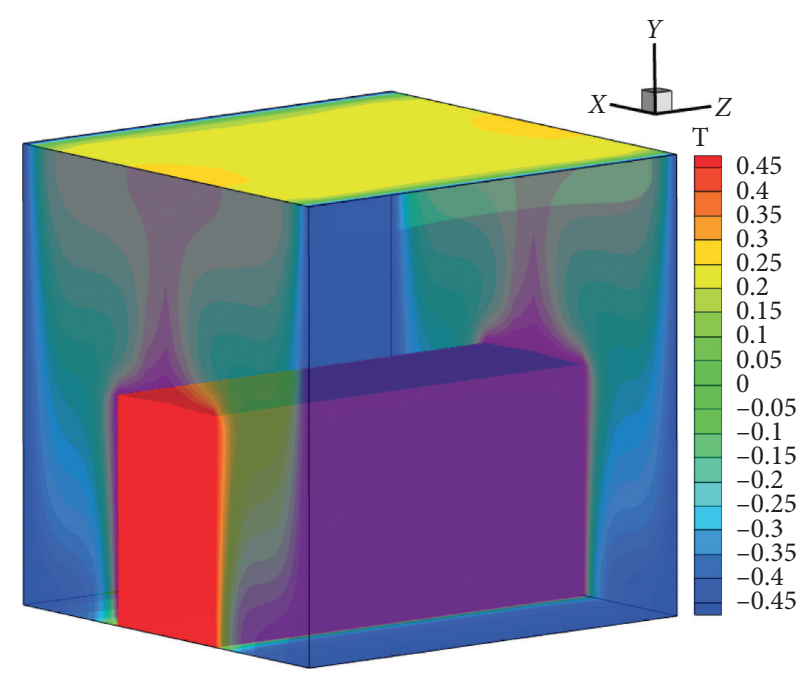

(d)

Figure 3: 3D temperature field for $\phi=0.04$ of the $\mathrm{Al}_{2} \mathrm{O}_{3}$. (a) $d=0.25$. (b) $d=0.5$. (c) $d=0.75$. (d) $d=1$.
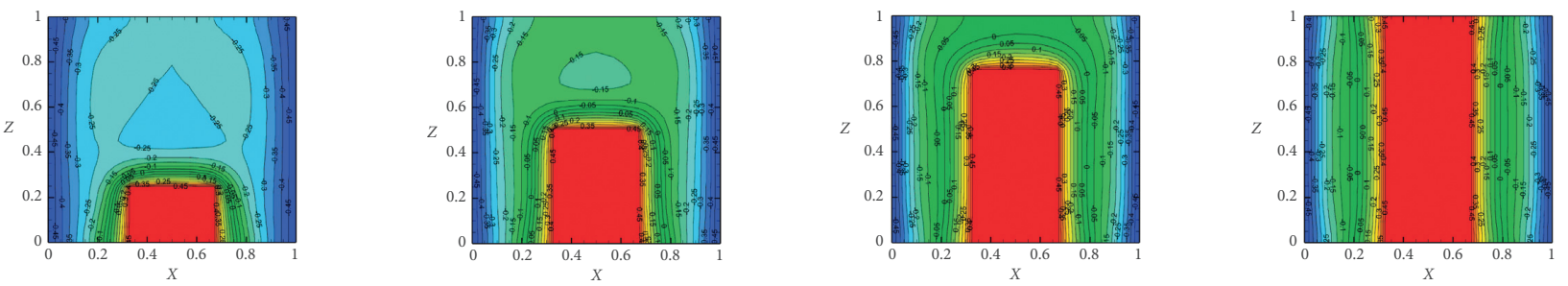

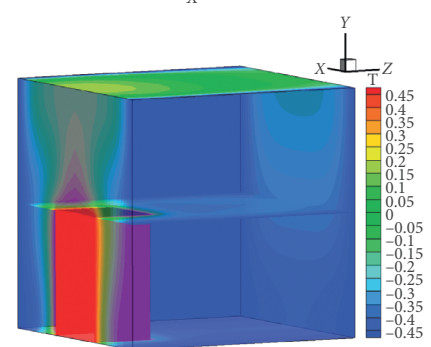

(a)

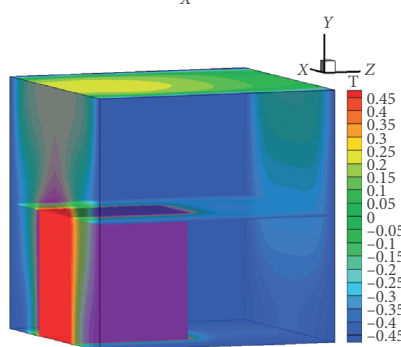

(b)

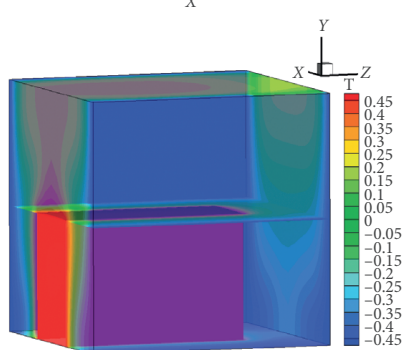

(c)

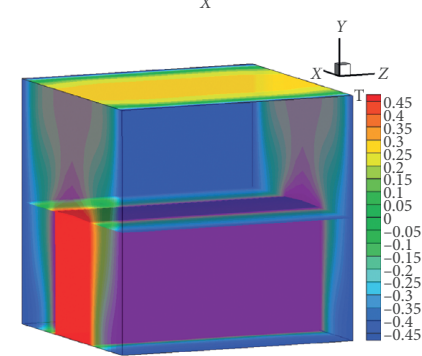

(d)

FIgURE 4: Isotherms for (water- $\mathrm{Al}_{2} \mathrm{O}_{3}$ ) $\mathrm{Ra}=10^{5}, \phi=4 \%$, and different lengths $\mathrm{d}$ according to plane $Y=0.5$. (a) $d=0.25$. (b) $d=0.5$. (c) $d=0.75$. (d) $d=1$. 

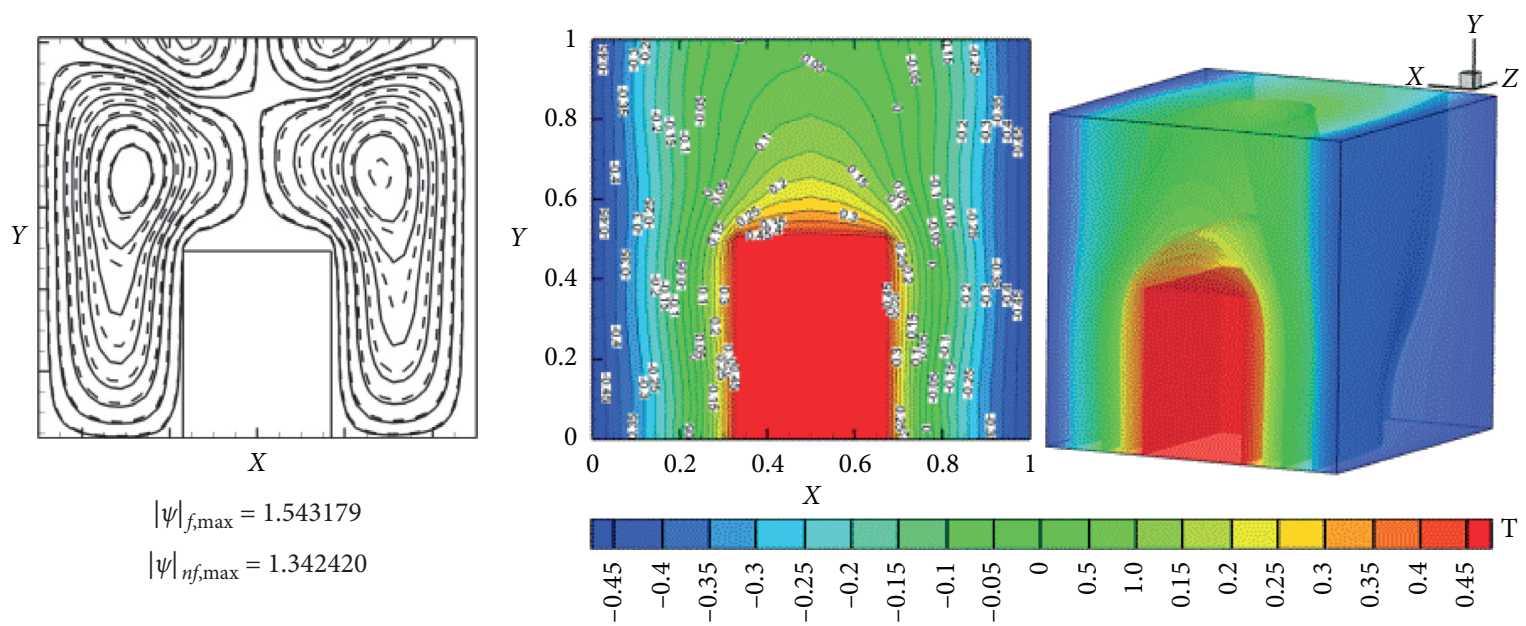

(a)
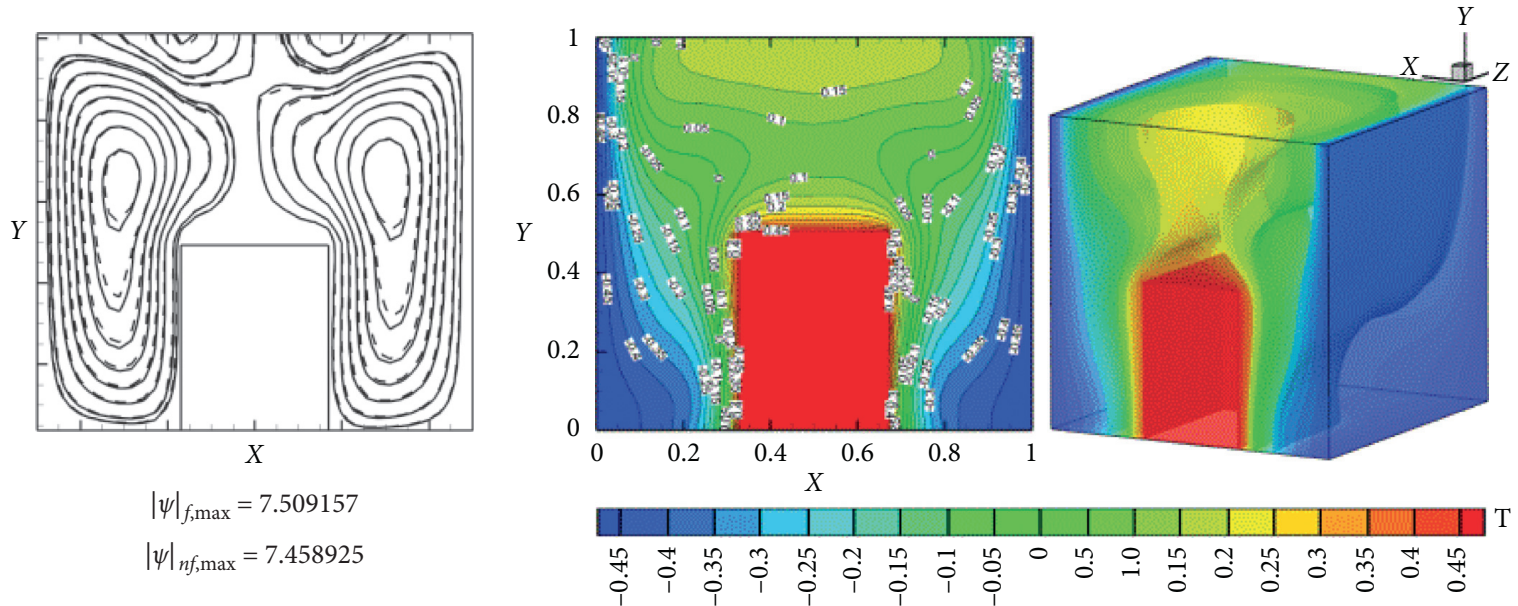

(b)
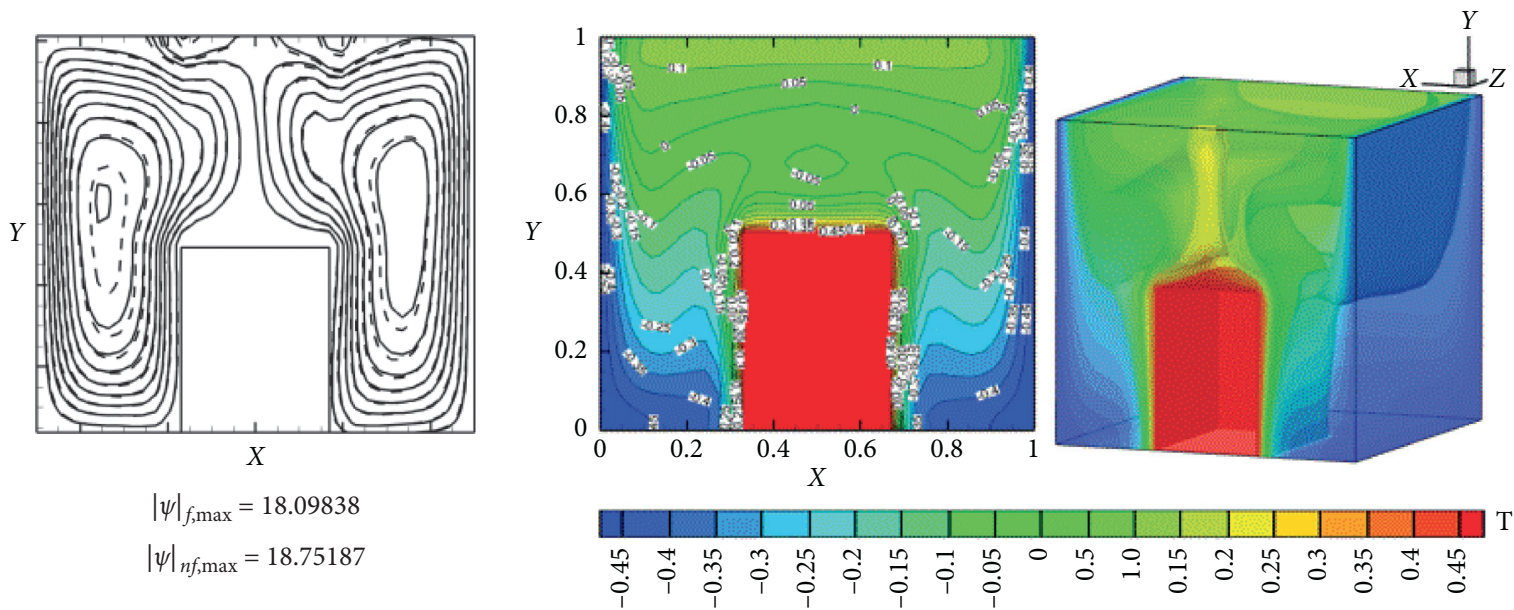

(c)

FIGURE 5: Streamlines and isotherms in the cavity for nanofluid $\left(\mathrm{Al}_{2} \mathrm{O}_{3}\right)$ and pure water, length $d=0.5$ and $\phi=0.04$ in plane $Z=1 / 2$. (a) $\mathrm{Ra}=10^{4}$. (b) $\mathrm{Ra}=10^{5}$. (c) $\mathrm{Ra}=10^{6}$.

and then the heat transfer. Figure 6 illustrates the isotherms and the streamlines for different types of nanoparticles $\left(\mathrm{Al}_{2} \mathrm{O}_{3}, \mathrm{Cu}\right.$, and $\left.\mathrm{TiO}_{2}\right)$ and a pure fluid in the $Z=1 / 2$ plane, the volume fractions varying between 0 and 0.04 , and the
Rayleigh number $\left(\mathrm{Ra}=10^{4}, 10^{5}\right.$, and $\left.10^{6}\right)$. The comparison between the nanofluids and the pure fluid shows a significant deviation of the isotherms by increasing the Rayleigh number and the volume fraction. For $\mathrm{Ra}=10^{3}$, these 


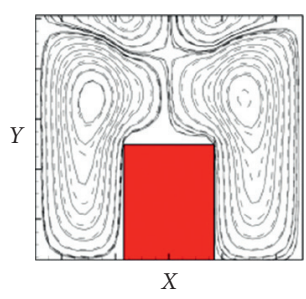

$|\psi|_{f, \text { max }}=7,509157$

$|\psi|_{n f \text { max }}=7,458925$

(a)

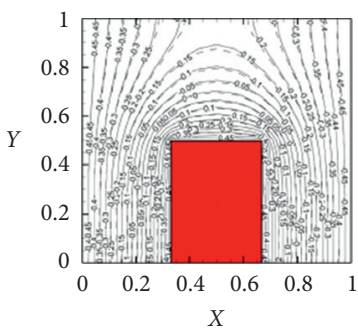

(d)

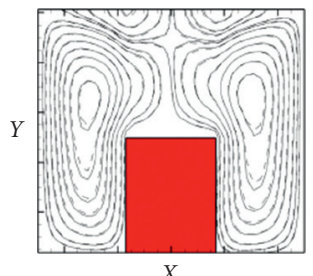

$|\psi|_{f, \max }=7,509157$

$|\psi|_{\text {nf, } \text { max }}=7,458925$

(g)

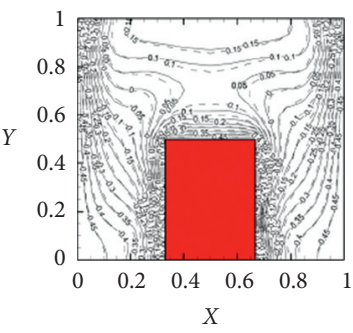

(j)

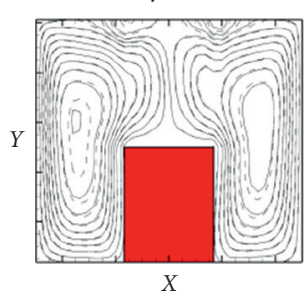

$\begin{aligned}|\psi|_{f, \text { max }} & =18,09838 \\ |\psi|_{\text {nfmax }} & =18,75187\end{aligned}$

(m)

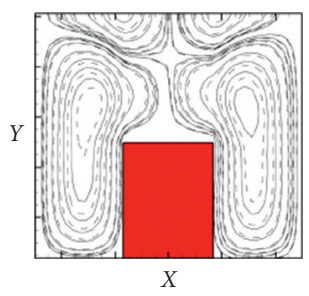

$|\psi|_{f, \max }=7,509157$

$|\psi|_{n f, \max }=7,569393$

(b)

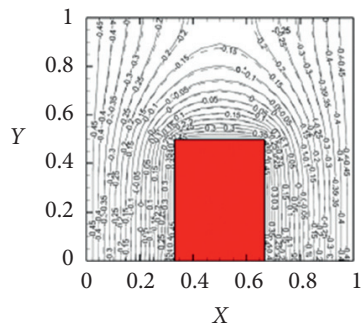

(e)

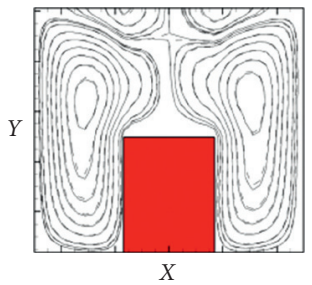

$|\psi|_{f, \max }=7,509157$

$|\psi|_{\text {nf,max }}=7,569393$

(h)

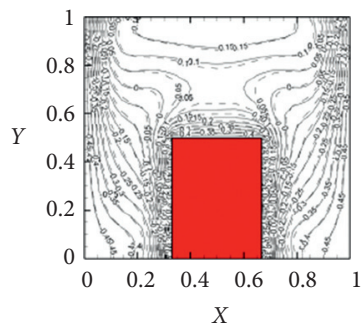

(k)

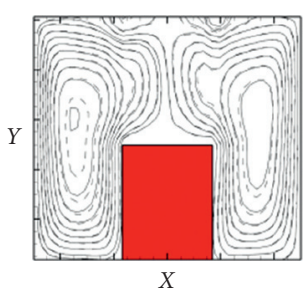

$|\psi|_{f, \text { max }}=18,09838$

$|\psi|_{\text {nf, } \text { max }}=18,75187$

(n)

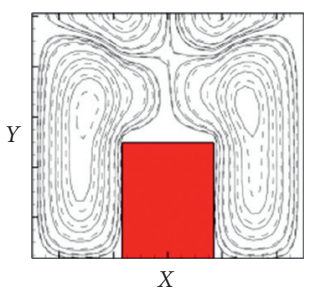

$|\psi|_{\text {, max }}=7,509157$

$|\psi|_{n f \text { max }}=7,410663$

(c)

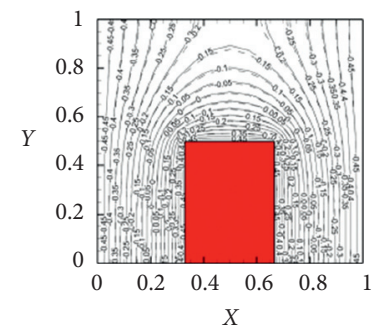

(f)

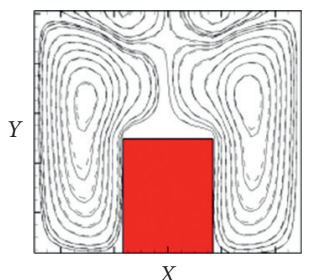

$|\psi|_{f, \text { max }}=7,509157$

$|\psi|_{\text {nf, max }}=7,410663$

(i)

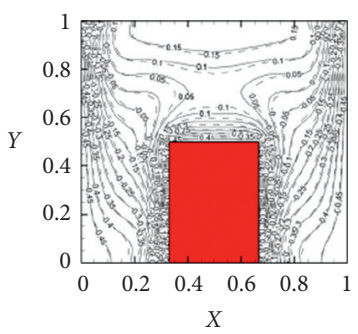

(1)

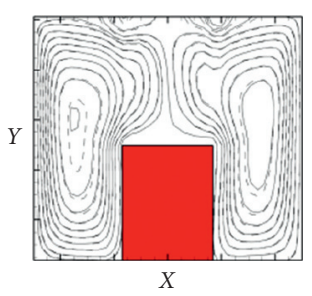

$|\psi|_{f, \text { max }}=18,09838$

$|\psi|_{n f, \text { max }}=18,57277$

(o)

Figure 6: Continued. 


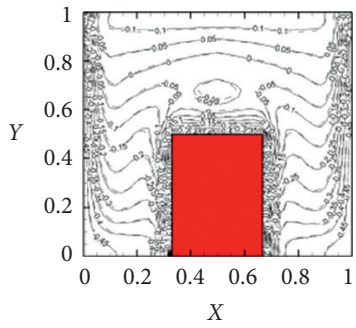

(p)

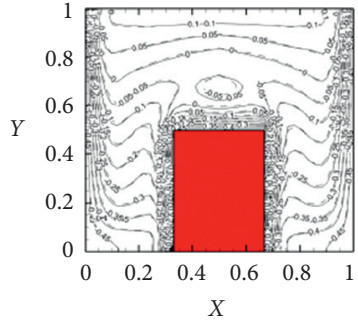

(q)

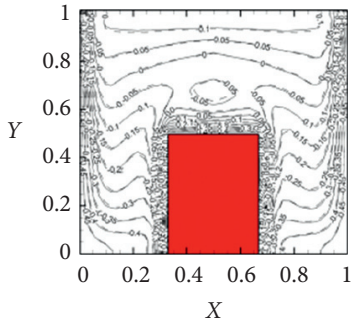

(r)

Figure 6: Streamlines (top: (a, b, c), (g, h, i) and ( $\mathrm{m}, \mathrm{n}, \mathrm{o})$ respectively for $\mathrm{Ra}=10^{3}, \mathrm{Ra}=10^{5}$ and $\left.\mathrm{Ra}=10^{6}\right)$ and isotherms (bottom: $(\mathrm{d}, \mathrm{e}, \mathrm{f}),(\mathrm{j}$, $\mathrm{k}, \mathrm{l})$ and $(\mathrm{p}, \mathrm{q}, \mathrm{r})$ respectively for $\mathrm{Ra}=10^{3}, \mathrm{Ra}=10^{5}$ and $\left.\mathrm{Ra}=10^{6}\right)$ for pure water $(-)$ and for different nanofluids $(---)\left(\mathrm{Al}_{2} \mathrm{O}_{3}(\mathrm{a}, \mathrm{d}, \mathrm{g}, \mathrm{j}, \mathrm{m}\right.$ and $\mathrm{p}), \mathrm{Cu}(\mathrm{b}, \mathrm{e}, \mathrm{h}, \mathrm{k}, \mathrm{n}$ and $\mathrm{q})$ and $\mathrm{TiO}_{2}(\mathrm{c}, \mathrm{f}, \mathrm{i}, \mathrm{l}, \mathrm{o}$ and $\mathrm{r})$ ) in the plane $Z=1 / 2$.

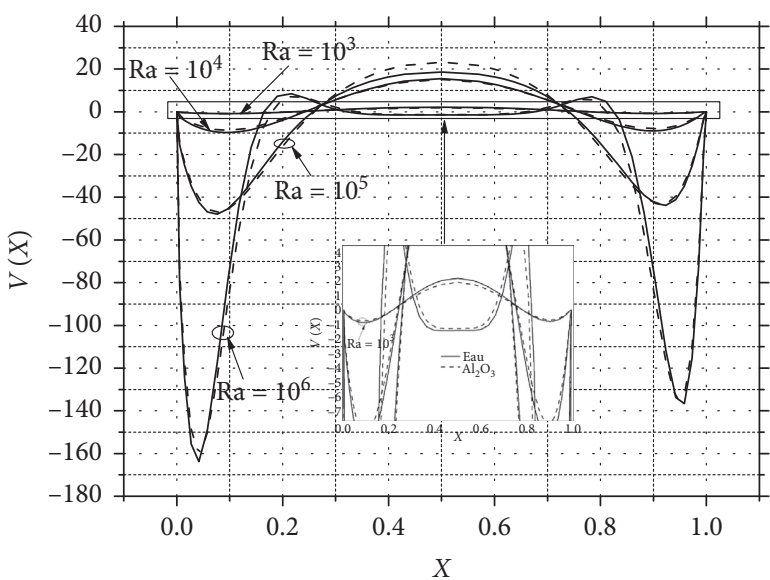

- Eau

$---\mathrm{Al}_{2} \mathrm{O}_{3}$

(a)

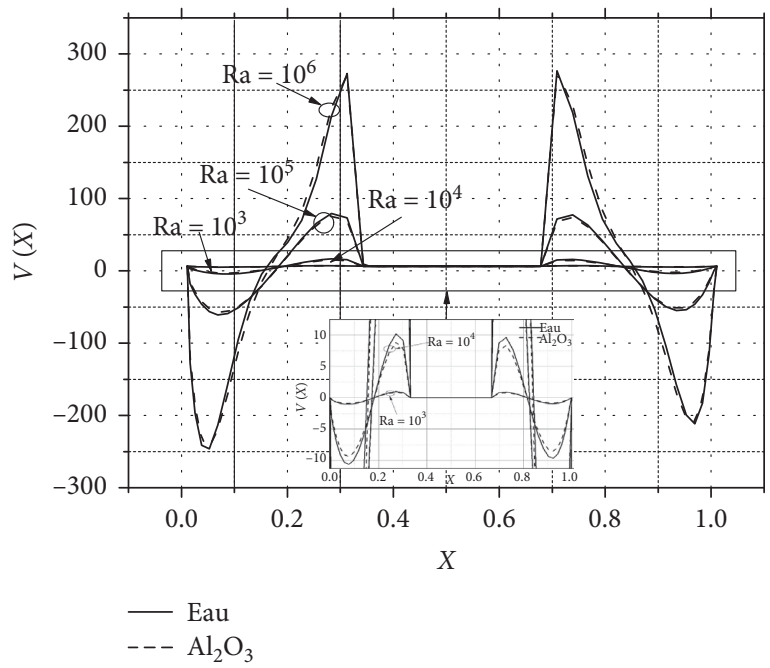

(c)

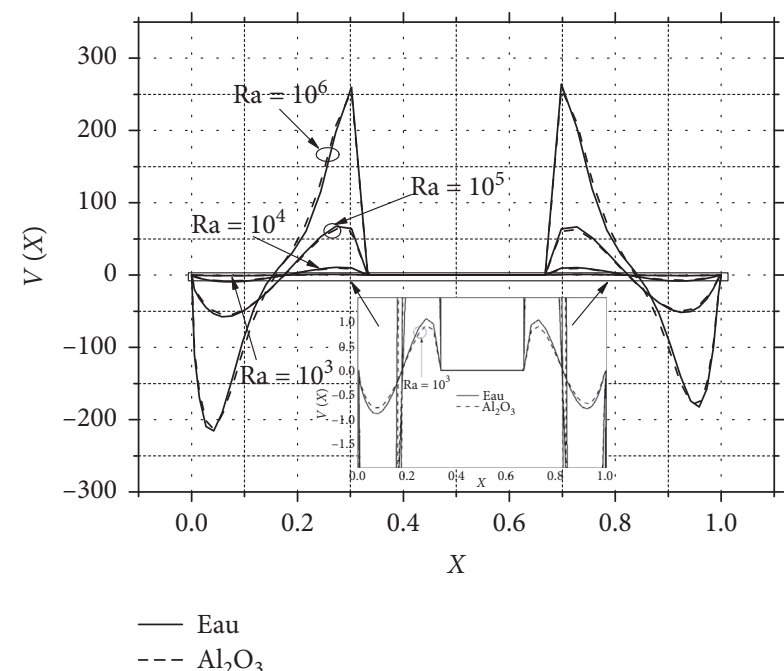

(b)

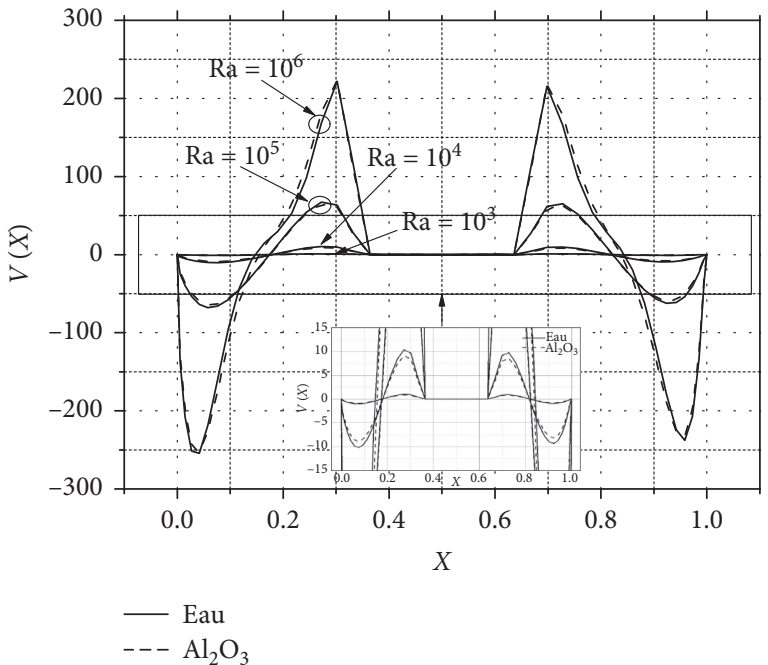

(d)

FIgURE 7: Profiles of the vertical component of the velocity $(V)$ along the horizontal median of the enclosure for water- $\mathrm{Al}_{2} \mathrm{O}_{3}$ and different lengths. (a) $d=0.25$. (b) $d=0.5$. (c) $d=0.75$. (d) $d=1$. 


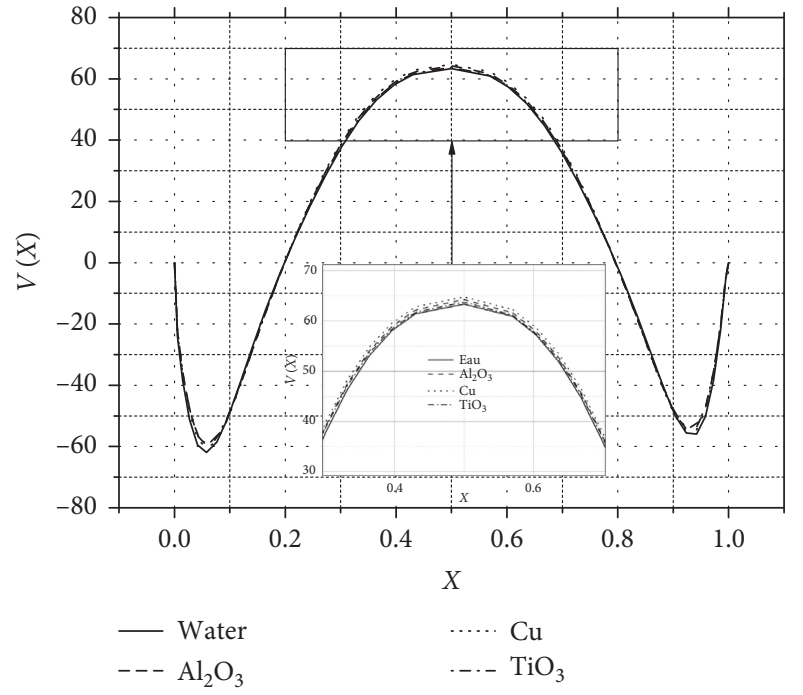

(a)

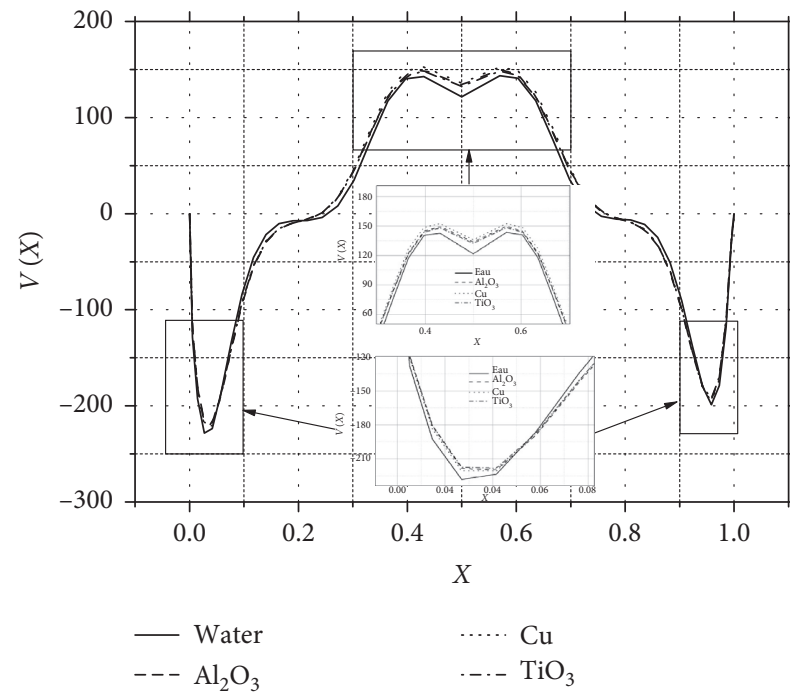

(b)

FIGURE 8: Vertical component of the velocity along the horizontal median plane for pure water and different nanofluid. $(\mathrm{a}) \mathrm{Ra}=10^{5}$. $(\mathrm{b}) \mathrm{Ra}=10^{6}$.

isotherms are nearly parallel to the vertical walls, indicating that, for small values of the Rayleigh number, the heat transfer is practically conductive. For $\mathrm{Ra}=10^{5}$, the isotherms are slightly deformed with a small variation following $y$. Beyond this value of $\mathrm{Ra}$, the deformation of the isotherms becomes more evident and horizontal stratification begins to settle in the center of the cavity. For $\mathrm{Ra}=10^{6}$, we notice that the vertical gradient of the temperature becomes almost constant at the heart of the cavity and subsequently a horizontal stratification settles there. The values of $\psi$ (the function of the current) increase with the increasing of Rayleigh number. Thus, it is shown that the flow of the pure fluid is stronger than that of the nanofluid for $\mathrm{Ra}=10^{3}$. The streamlines become tighter close to the sidewalls, and the shape of the cells changes completely for $\mathrm{Ra} \geq 10^{5}$. The flow of the nanofluids becomes stronger. According to this figure, the water and the different mixtures have the same dynamic and thermal behavior. Furthermore, Figure 6 confirms that the copper nanoparticles allow a better heat exchange by comparing with Alumina and Titanium and the type of nanoparticles is a main factor for the improvement of the heat transfer.

4.3. Velocity. In order to justify more the flow of the fluid in the cavity, Figure 7 shows the profiles of the vertical component of the velocity $(V)$ along the horizontal median of the enclosure, for different lengths and Rayleigh numbers; it increases under the effect of the buoyancy force with the increase of Ra. We observe a decrease in the intensity of the fluid flow at the cold side walls and an increase in the heated walls. This rise increases with Rayleigh number and reaches its maximum at the center of the heated walls, where the temperature is maximum. This is due to the increase in the intensity of the thermal thrust forces and therefore to the predominance of convective heat transfer. In addition, it is useful to mention that the flow becomes stagnant in the $0.35 \leq X \leq 0.65$ zone where the heating partition is located, and this is for all lengths $d \geq 0.5$. It is also observed that the behavior of the dynamic field is symmetrical with respect to the plane $X=0.5$. Therefore, the fluid is heated significantly and relaxes with a decrease in density. It follows a rise of the fluid upwards and the speed of the flow becomes important.

Figure 8 shows the vertical component velocity profiles at the center line for different Rayleigh number values $\left(\mathrm{Ra}=10^{3}, 10^{4}, 10^{5}\right.$, and $\left.10^{6}\right)$ and different nanofluids. From this figure, we notice that the vertical velocity $(V)$ reaches a maximum value near the adiabatic sidewalls, for all types of nanoparticles, where the fluid changes direction and $V$ decreases towards negative values. The difference between the three types of nanofluids is small and the vertical component of the velocity is not significantly affected by the type of nanoparticles. For $\mathrm{Ra}=10^{3}$, we observe that the values of the speed are higher in the case of base fluid, and the addition of nanoparticles contributes to slowing down of the fluid in the vertical direction. Decreasing speed results in a decrease in convective heat transfer. However, since much of the heat exchange is conducted by conduction, the decrease in the speed of the nanofluids has no visible influence on the overall heat transfer, which remains better than that of the water due to the high value of the thermal conductivity of the nanofluid. In the case of dominant convection $\left(\mathrm{Ra}=10^{6}\right)$, we observe that the velocities reached by nanofluids are greater than those corresponding to base fluid. Thus, the use of nanofluids modifies the velocity profiles and, as a result, the temperatures and the heat transfer are increased. When comparing the velocity profiles between the nanofluid and the base fluid, only 


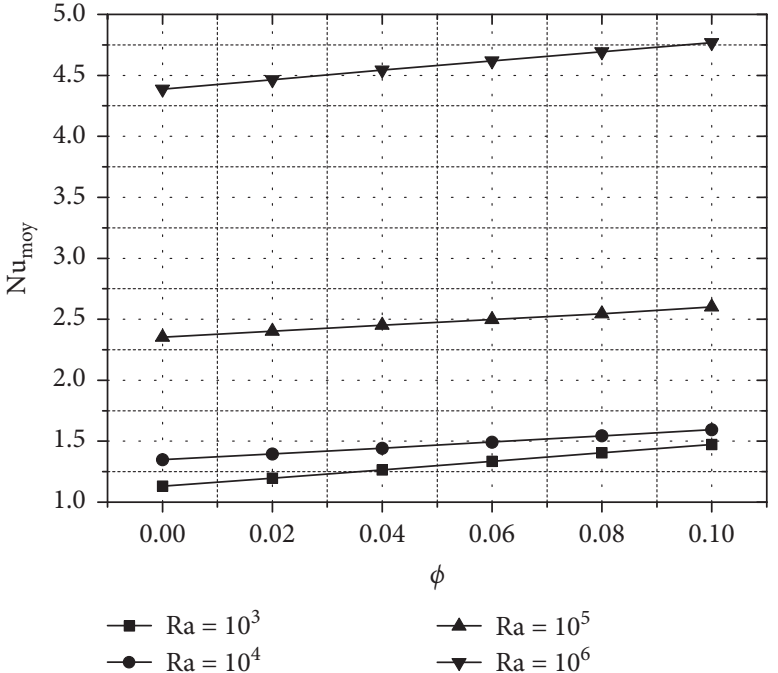

(a)

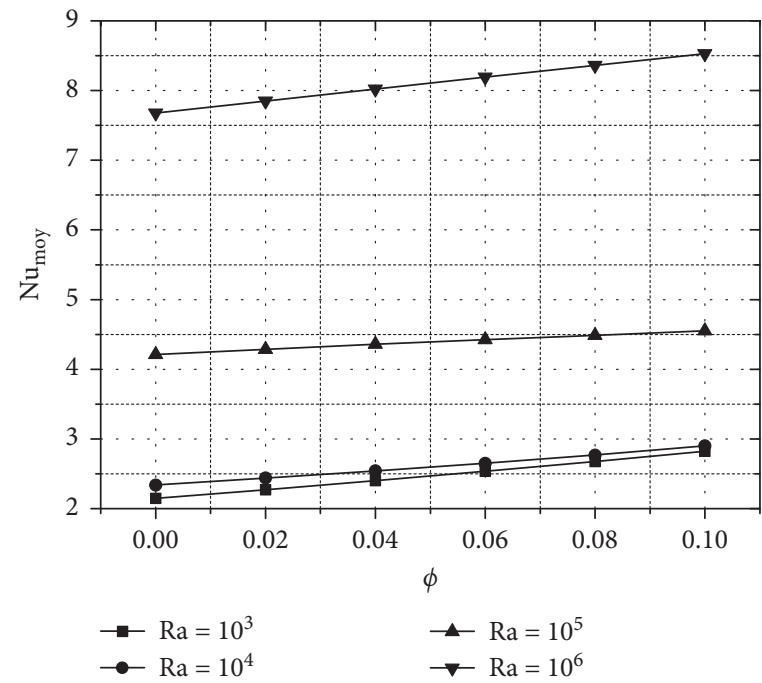

(c)

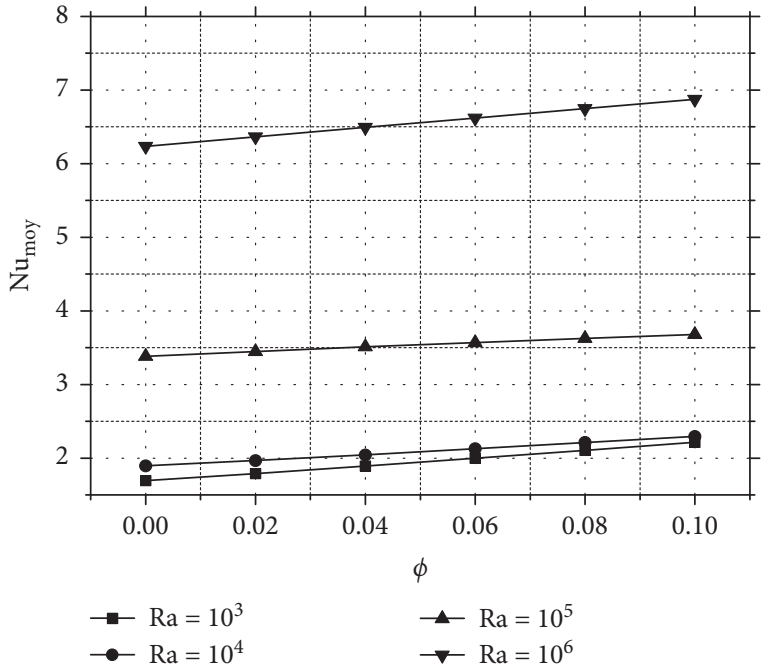

(b)

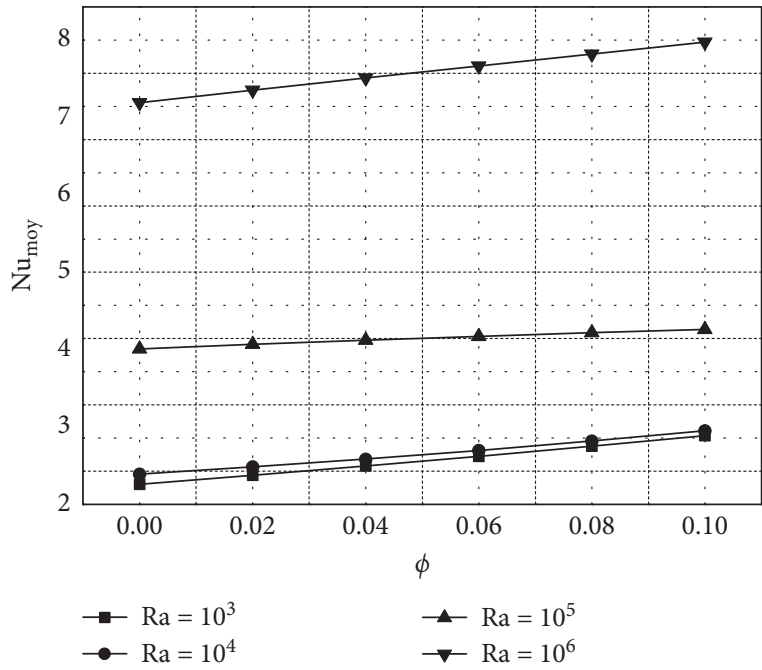

(d)

Figure 9: The variation of the average Nusselt number as a function of the Rayleigh numbers, and $\phi$ for water- $\mathrm{Al}_{2} \mathrm{O}_{3}$. (a) $d=0.25$. (b) $d=0.5$. (c) $d=0.75$. (d) $d=0.1$.

small differences are observed. It is concluded that the $V$ (y) components of the velocity are not sensitive to the type of nanofluid.

4.4. Average Nusselt Number. The results presented in this part are obtained for Rayleigh numbers Ra between $10^{3}$ and $10^{6}$, different volume fractions of the nanoparticles, and length of the partition. Subsequently, we will focus on the effect of these parameters on the average Nusselt number.

The variation of the average Nusselt number as a function of the length of the heated sources for different Rayleigh numbers is shown in Figure 9. It is noted that, regardless of length and form of the heated sources, the average Nusselt number increases with the increase of the volume fraction. This increase is due to the improvement of the thermal conductivity of the nanofluid. The effect of the nanoparticles is greater at low $\mathrm{Ra}$ values, so that the $6 \%$ increase in the volume fraction for a length of 0.5 leads to a relative increase in the average Nusselt number of about $9 \%$ for $\mathrm{Ra}=10^{6}$ and about $26 \%$ for $\mathrm{Ra}=10^{3}$. The figure also shows that, for a given volume fraction, the average Nusselt increases with the increase in $\mathrm{Ra}$ and the length of the block.

Figure 10 shows the variation of the average Nusselt number for different values of $\mathrm{Ra}$, as a function of the volume fraction of the $\mathrm{Al}_{2} \mathrm{O}_{3}, \mathrm{Cu}$, and $\mathrm{TiO}_{2}$. We note that $\mathrm{Nu}_{\mathrm{av}}$ increases with $\mathrm{Ra}$ and the volume fraction of the nanoparticles. This is due to the improvement of the $k_{n f}$, when the volume fraction of the nanoparticles increases. We observe, in a general way, that the intensification of the thermal thrust forces, through the increase of the number of Rayleigh, favors the thermal exchanges within the cavity and this is because of the increase of the speed 


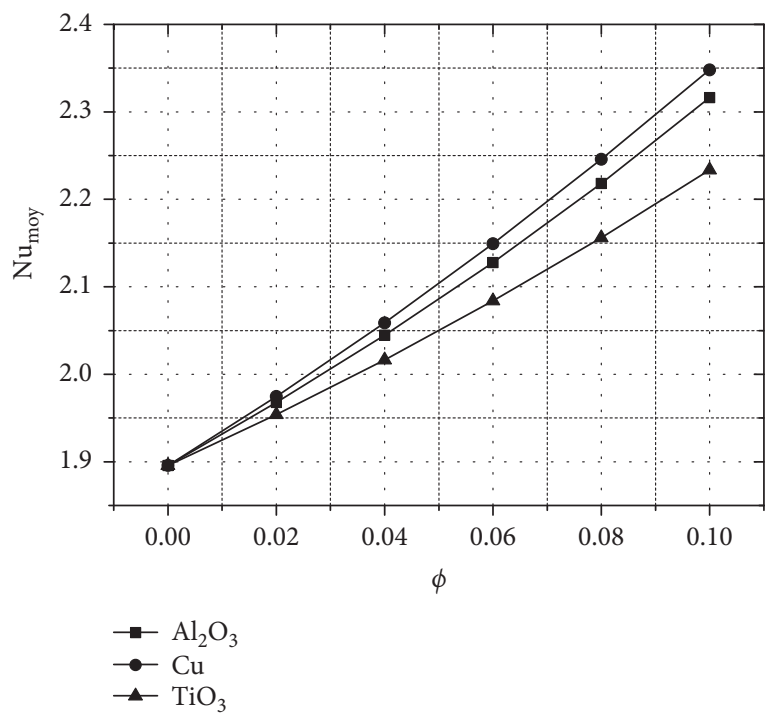

(a)

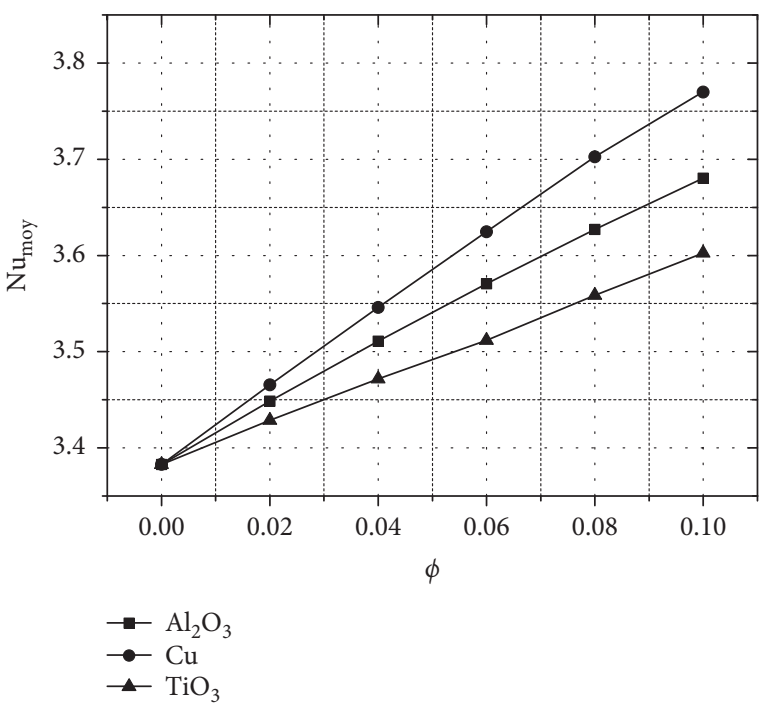

(b)

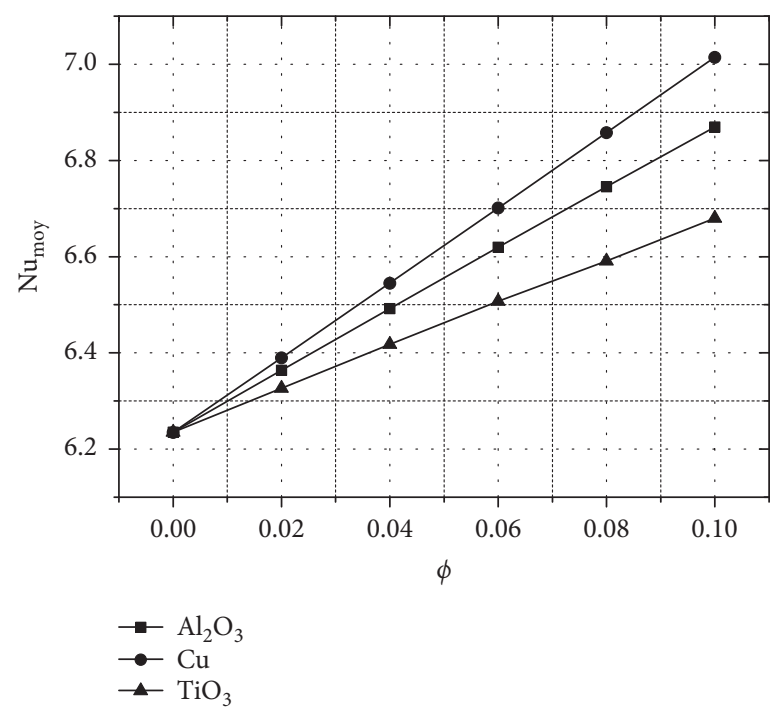

(c)

FIgURE 10: Variation of the average Nusselt number as a function of the volume fraction and nanofluid type for different Ra. (a) Ra $=10^{4}$. (b) $\mathrm{Ra}=10^{5}$. (c) $\mathrm{Ra}=10^{6}$.

(Figure 7) following the intensification of convection currents. This figure also shows the effect of the nanoparticles type on the variation of the average Nusselt number. This heat transfer rate is maximum in the case of water-Cu. A large number of Nusselt, that is to say, a stronger exchange, is favored by a higher conductivity to evacuate heat, a lower heat capacity to reduce storage, and a higher density to promote convection (force Archimedes). These parameters play in favor of copper in comparison with $\mathrm{Al}_{2} \mathrm{O}_{3}$ and $\mathrm{TiO}_{2}$ nanoparticles. Indeed, the latter nanoparticles have very close heat capacities and densities (difference not exceeding 12\%), but the thermal conductivity of $\mathrm{Al}_{2} \mathrm{O}_{3}$ is greater than that of $\mathrm{TiO}_{2}$ by about $34.6 \%$, according to the results of Glades [42]. As a result,
$\mathrm{Al}_{2} \mathrm{O}_{3}$ nanoparticles provide better heat transfer than $\mathrm{TiO}_{2}$ nanoparticles.

\section{Conclusion}

The study presented in this article deals with the natural laminar convection of nanofluids within a three-dimensional cavity containing two heating portions located on the left wall. In the first part of this paper, we analyzed the effect of various parameters on heat transfer, namely, the volume fraction, the Rayleigh number, and the height of the heat source. This allowed us to highlight the effect generated by each parameter and to identify the optimal situations favoring heat transfer. In the second part, we made a comparison between three 
types of nanoparticles (copper $(\mathrm{Cu})$, aluminum oxide $\left(\mathrm{Al}_{2} \mathrm{O}_{3}\right)$, and titanium oxide $\left.\left(\mathrm{TiO}_{2}\right)\right)$.

The main results can be summarized as follows:

(i) The effect of the nanofluid on natural convection is particularly apparent at high Rayleigh numbers.

(ii) The increase in the volume fraction causes the intensification of the flow and an increase of the heat exchange.

(iii) The heat transfer in the presence of copper nanoparticles is greater than that of $\mathrm{Al}_{2} \mathrm{O}_{3}$ and $\mathrm{TiO}_{2}$ nanoparticles; therefore, the type of nanoparticles is a main factor in improving heat transfer.

(iv) The geometry parameters (dimensionless length and width of the heat source) are used to improve heat transfer. As the length of the heat source increases, the average Nusselt number increases.

(v) As the Rayleigh number increases, the buoyancy force becomes important and therefore the maximum flow function of the pure fluid and the nanofluid increases. The flow in the presence of nanofluid is more intense than that of the pure fluid for Ra greater than $10^{4}$.

(vi) From all the previous investigations, we can say that the case which improves the thermal and dynamic transfers is the one where the length of the partition is $d=1$. We get the best heat transfer for this case, so we can say that it is the optimal choice.

This configuration is the optimal choice to obtain the best heat transfer, because the thermal and dynamic transfers are influenced by the heat exchange surface and the value of the buoyancy force which is favourable in the case of the length being $d=1$.

\section{Nomenclature}

d: $\quad$ Dimensionless heat source length

E: Dimensionless heat source height

e: $\quad$ Dimensionless heat source width

$C_{P}: \quad$ Specific heat $\left(\mathrm{J} \cdot \mathrm{kg}^{-1} \cdot \mathrm{K}^{-1}\right)$

$g$ : $\quad$ Gravitational acceleration $\left(\mathrm{m} \cdot \mathrm{s}^{-2}\right)$

$k$ : Thermal conductivity $\left(\mathrm{W} \cdot \mathrm{m}^{-1} \cdot \mathrm{K}^{-1}\right)$

$\mathrm{Nu}_{\mathrm{av}}$ : Local Nusselt number along the heat source

Ra: $\quad$ Rayleigh number

Pr: $\quad$ Prandtl number

$H$ : $\quad$ Height of the cavity

$B$ : $\quad$ Length of the cavity

$B$ : Width of the cavity

$u, v, w$ : Dimensional velocities $(\mathrm{m} / \mathrm{s})$

$U, V, W$ : Dimensionless velocities

$P$ : $\quad$ Dimensionless pressure

$x, y, z: \quad$ Dimensional coordinates (m)

$X, Y, Z:$ Dimensionless coordinates

Subscripts

np: Nanoparticle

$f: \quad$ Fluid (pure water)

nf: Nanofluid
Greek symbols

$\alpha$ : Thermal diffusivity $\left(\mathrm{m}^{2} \cdot \mathrm{S}^{-1}\right)$

$\beta$ : Thermal expansion coefficient $\left(\mathrm{K}^{-1}\right)$

$v$ : Kinematic viscosity $\left(\mathrm{m}^{2} / \mathrm{s}\right)$

$\rho:$ Density $\left(\mathrm{kg} / \mathrm{m}^{3}\right)$

$k$ : Thermal conductivities $\left(\mathrm{W} \cdot \mathrm{m}^{1} \cdot \mathrm{K}^{1}\right)$

$\phi$ : Solid volume fraction

$\Theta$ : Dimensionless temperature

$\mu$ : Dynamic viscosity $\left(\mathrm{kg} \cdot \mathrm{m}^{-1} \cdot \mathrm{s}^{-1}\right)$

$H$ : Hot

C: Cold.

\section{Data Availability}

The data are available upon request to the corresponding author.

\section{Conflicts of Interest}

The authors declare that they have no conflicts of interest.

\section{References}

[1] K. Khanafer, K. Vafai, and M. Lightstone, "Buoyancy-driven heat transfer enhancement in a two-dimensional enclosure utilizing nanofluids," International Journal of Heat and Mass Transfer, vol. 46, no. 19, pp. 3639-3653, 2003.

[2] S. M. S. Murshed, K. C. Leong, and C. Yang, "Enhanced thermal conductivity of $\mathrm{TiO}_{2}$-water based nanofluids," International Journal of Thermal Sciences, vol. 44, no. 4, pp. 367-373, 2005.

[3] R.-Y. Jou and S.-C. Tzeng, "Numerical research of nature convective heat transfer enhancement filled with nanofluids in rectangular enclosures," International Communications in Heat and Mass Transfer, vol. 33, no. 6, pp. 727-736, 2006.

[4] C. J. Ho, M. W. Chen, and Z. W. Li, "Numerical simulation of natural convection of nanofluid in a square enclosure: effects due to uncertainties of viscosity and thermal conductivity," International Journal of Heat and Mass Transfer, vol. 51, no. 17-18, pp. 4506-4516, 2008.

[5] Y. Hwang, H. S. Park, J. K. Lee, and W. H. Jung, "Thermal conductivity and lubrication characteristics of nanofluids," Current Applied Physics, vol. 6, pp. e67-e71, 2006.

[6] H. F. Oztop and E. Abu-Nada, "Numerical study of natural convection in partially heated rectangular enclosures filled with nanofluids," International Journal of Heat and Fluid Flow, vol. 29, no. 5, pp. 1326-1336, 2008.

[7] S. Anilkumar and G. Jilani, "Convective heat transfer enhancement in an enclosure with fin utilizing nanofluids," International Journal of Mechanical, Industrial and Aerospace Engineering, vol. 3, no. 2, pp. 104-111, 2009.

[8] E. B. Öğüt, "Natural convection of water-based nanofluids in an inclined enclosure with a heat source," International Journal of Thermal Sciences, vol. 48, no. 11, pp. 2063-2073, 2009.

[9] A. K. Hussein, H. R. Ashorynejad, M. Shikholeslami, and S. Sivasankaran, "Lattice Boltzmann simulation of natural convection heat transfer in an open enclosure filled with $\mathrm{Cu}-$ water nanofluid in a presence of magnetic field," Nuclear Engineering and Design, vol. 268, pp. 10-17, 2014.

[10] A. K. Hussein and S. H. Hussain, "Heatline visualization of natural convection heat transfer in an inclined wavy cavities filled with nanofluids and subjected to a discrete isoflux 
heating from its left sidewall," Alexandria Engineering Journal, vol. 55, no. 1, pp. 169-186, 2016.

[11] A. K. Hussein, M. A. Y. Bakier, M. B. B. Hamida, and S. Sivasankaran, "Magneto-hydrodynamic natural convection in an inclined T-shaped enclosure for different nanofluids and subjected to a uniform heat source," Alexandria Engineering Journal, vol. 55, no. 3, pp. 2157-2169, 2016.

[12] A. K. Hussein and A. W. Mustafa, "Natural convection in fully open parallelogrammic cavity filled with $\mathrm{Cu}$-water nanofluid and heated locally from its bottom wall," Thermal Science and Engineering Progress, vol. 1, pp. 66-77, 2017.

[13] A. K. Hussein and A. W. Mustafa, "Natural convection in a parabolic enclosure with an internal vertical heat source filled with Cu-water nanofluid," Heat Transfer-Asian Research, vol. 47, no. 2, pp. 320-336, 2018.

[14] A. A. Al-Rashed, K. Kalidasan, L. Kolsi, M. N. Borjini, and P. R. Kanna, "Three-dimensional natural convection of CNTwater nanofluid confined in an inclined enclosure with Ahmed body," Journal of Thermal Science and Technology, vol. 12, no. 1, Article ID JTST0002, 2017.

[15] A. A. Al-Rashed, L. Kolsi, M. A. Tashkandi, E. H. Malekshah, A. J. Chamkha, and M. N. Borjini, "Three-dimensional combined radiation-magnetoconvection of low electrically conductive dielectric oxide melt," International Journal of Numerical Methods for Heat \& Fluid Flow, vol. 29, no. 10, 2019.

[16] R. Chand, G. Rana, and A. K. Hussein, "On the onsetof thermal instability in a low Prandtl number nanofluid layer in a porous medium," Journal of Applied Fluid Mechanics, vol. 8, no. 2, pp. 265-272, 2015.

[17] A. K. Hussein, K. Lioua, R. Chand et al., "Three-dimensional unsteady natural convection and entropy generation in an inclined cubical trapezoidal cavity with an isothermal bottom wall," Alexandria Engineering Journal, vol. 55, no. 2, pp. 741-755, 2016.

[18] A. K. Hussein, L. Kolsi, M. A. Almeshaal, D. Li, H. M. Ali, and I. S. Ahmed, "Mixed convection in a cubical cavity with active lateral walls and filled with hybrid graphene-platinum nanofluid," Journal of Thermal Science and Engineering Applications, vol. 11, no. 4, 2019.

[19] L. Kolsi, H. Oztop, K. Ghachem et al., "Numerical study of periodic magnetic field effect on $3 \mathrm{D}$ natural convection of MWCNT-water/nanofluid with consideration of aggregation," Processes, vol. 7, no. 12, p. 957, 2019.

[20] R. U. Haq, F. A. Soomro, Z. Hammouch, and S. U. Rehman, "Heat exchange within the partially heated C-shape cavity filled with the water based SWCNTs," International Journal of Heat and Mass Transfer, vol. 127, pp. 506-514, 2018.

[21] R. u. Haq and S. Aman, "Water functionalized $\mathrm{CuO}$ nanoparticles filled in a partially heated trapezoidal cavity with inner heated obstacle: FEM approach," International Journal of Heat and Mass Transfer, vol. 128, pp. 401-417, 2019.

[22] R. U. Haq, F. A. Soomro, T. Mekkaoui, and Q. M. Al-Mdallal, "MHD natural convection flow enclosure in a corrugated cavity filled with a porous medium," International Journal of Heat and Mass Transfer, vol. 121, pp. 1168-1178, 2018.

[23] N. Muhammad, S. Nadeem, and A. Issakhov, "Finite volume method for mixed convection flow of Ag-ethylene glycol nanofluid flow in a cavity having thin central heater," Physica A: Statistical Mechanics and Its Applications, vol. 537, Article ID 122738, 2020.

[24] M. Hashemi-Tilehnoee, A. S. Dogonchi, S. M. Seyyedi, A. J. Chamkha, and D. D. Ganji, "Magnetohydrodynamic natural convection and entropy generation analyses inside a nanofluid-filled incinerator-shaped porous cavity with wavy heater block," Journal of Thermal Analysis and Calorimetry, vol. 141, pp. 2033-2045, 2020.

[25] H. Bazdar, D. Toghraie, F. Pourfattah, O. A. Akbari, H. M. Nguyen, and A. Asadi, "Numerical investigation of turbulent flow and heat transfer of nanofluid inside a wavy microchannel with different wavelengths," Journal of Thermal Analysis and Calorimetry, vol. 139, no. 3, pp. 2365-2380, 2020.

[26] A. I. Alsabery, M. A. Ismael, A. J. Chamkha, and I. Hashim, "Effect of nonhomogeneous nanofluid model on transient natural convection in a non-Darcy porous cavity containing an inner solid body," International Communications in Heat and Mass Transfer, vol. 110, Article ID 104442, 2020.

[27] J. Guiet, M. Reggio, and P. Vasseur, "Natural convection of nanofluids in a square enclosure with a protruding heater," Advances in Mechanical Engineering, vol. 2012, Article ID 167296, 11 pages, 2012.

[28] H. C. Brinkman, "The viscosity of concentrated suspensions and solution," Journal of Chemical Physics, vol. 20, no. 65, pp. 863-869, 2005.

[29] H. E. Patel, K. B. Anoop, T. Sundararajan, and S. K. Das, “A micro-convection model for thermal conductivity of nanofluids," in Proceedings of the 2006 International Heat Transfer Conference, Sydney, Australia, 2006.

[30] M. A. Almeshaal, K. Kalidasan, F. Askri, R. Velkennedy, A. S. Alsagri, and L. Kolsi, "Three-dimensional analysis on natural convection inside a T-shaped cavity with water-based CNT-aluminum oxide hybrid nanofluid," Journal of Thermal Analysis and Calorimetry, vol. 139, no. 3, pp. 2089-2098, 2020.

[31] A. Izadi, M. Siavashi, H. Rasam, and Q. Xiong, "MHD enhanced nanofluid mediated heat transfer in porous metal for CPU cooling," Applied Thermal Engineering, vol. 168, Article ID 114843, 2020.

[32] A. Baïri, "Experimental study on enhancement of free convective heat transfer in a tilted hemispherical enclosure by using water-ZnO nanofluid saturated porous materials," Applied Thermal Engineering, vol. 148, pp. 992-998, 2019.

[33] H. R. Kataria and A. S. Mittal, "Mathematical analysis of three dimensional nanofluid flow in a rotating system considering thermal interfacial resistance and Brownian motion in suspensions through porous medium," Mathematics Today, vol. 34, pp. 7-24, 2018.

[34] O. Mahian, L. Kolsi, M. Amani et al., "Recent advances in modeling and simulation of nanofluid flows-Part I: fundamentals and theory," Physics Reports, vol. 790, pp. 1-48, 2019.

[35] M. Sannad, B. Abourida, L. Belarche, H. Doghmi, and M. Ouzaouit, "Effect of the heating block position on natural convection in a three-dimensional cavity filled with nanofluids," Journal of Applied Fluid Mechanics, vol. 12, no. 1, pp. 281-291, 2019.

[36] J. C. Maxwell, A Treatise on Electricity and Magnetism, Clarendon Press, Oxford, UK, 1881.

[37] J. Ravnik, L. Škerget, and M. Hriberšek, "Analysis of threedimensional natural convection of nanofluids by BEM," Engineering Analysis with Boundary Elements, vol. 34, no. 12, pp. 1018-1030, 2010.

[38] D. C. Lo, D. L. Young, K. Murugesan, C. C. Tsai, and M. H. Gou, "Velocity-vorticity formulation for 3D natural convection in an inclined cavity by DQ method," International Journal of Heat and Mass Transfer, vol. 50, no. 3-4, pp. 479-491, 2007.

[39] J.-P. Penot, "Calcul sous-differentiel et optimisation," Journal of Functional Analysis, vol. 27, no. 2, pp. 248-276, 1978. 
[40] S. Patankar, Numerical Heat Transfer and Fluid Flow, CRC Press, Boca Raton, FL, USA, 1980.

[41] S. V. Patankar and D. B. Spalding, "A calculation procedure for heat, mass and momentum transfer in three-dimensional parabolic flows," International Journal of Heat and Mass Transfer, vol. 15, no. 10, pp. 1787-1806, 1972.

[42] B. Gladés, "Contribution à l'étude de la convection naturelle dans les nanofluides en configuration de Rayleigh-Bénard," Doctoral thesis, Ecole Doctorale Mécanique, Energétique et Procédés (MEGeP), Unité de Recherche: UFR MIG-UPS/ IMFT, Université Toulouse, Toulouse, France, 2010. 